University of Louisville

ThinkIR: The University of Louisville's Institutional Repository

Electronic Theses and Dissertations

$5-2017$

\title{
The influence of sport participation on youth binge drinking.
}

Jason Nicholson

University of Louisville

Follow this and additional works at: https://ir.library.louisville.edu/etd

Part of the Social and Behavioral Sciences Commons

\section{Recommended Citation}

Nicholson, Jason, "The influence of sport participation on youth binge drinking." (2017). Electronic Theses and Dissertations. Paper 2624.

https://doi.org/10.18297/etd/2624

This Doctoral Dissertation is brought to you for free and open access by ThinkIR: The University of Louisville's Institutional Repository. It has been accepted for inclusion in Electronic Theses and Dissertations by an authorized administrator of ThinkIR: The University of Louisville's Institutional Repository. This title appears here courtesy of the author, who has retained all other copyrights. For more information, please contact thinkir@louisville.edu. 
THE INFLUENCE OF SPORT PARTICIPATION ON YOUTH BINGE DRINKING

\author{
By \\ Jason Nicholson \\ B.S. Eastern Kentucky University, 2011 \\ M.S. Eastern Kentucky University, 2013
}

\begin{abstract}
A Dissertation
Submitted to the Faculty of the

College of Arts and Sciences of the University of Louisville

In Partial Fulfillment of the Requirements

for the Degree of
\end{abstract}

Doctor of Philosophy

In Criminal Justice
Department of Criminal Justice
University of Louisville
Louisville, Kentucky

May 2017 
Copyright 2017 by Jason Nicholson

All rights reserved 



\title{
THE INFLUENCE OF SPORT PARTICAPTION ON YOUTH BINGE DRINKING
}

\author{
By
}

\author{
Jason Nicholson \\ B.S. Eastern Kentucky University, 2011 \\ M.S. Eastern Kentucky University, 2013
}

Dissertation Approved on

May 2, 2017

by the following Dissertation Committee:

Dr. Gennaro Vito

Dr. Cherie Dawson-Edwards

Dr. Martin Hall 


\section{DEDICATION}

This Dissertation is dedicated to my parents for their support. 


\section{ACKNOWLEDGMENTS}

I would like to thank my major professor, Dr. George E. Higgins for his guidance and patience. I would also like to thank the other committee members, Dr. Gennaro Vito, Dr. Dawson-Edwards, and Dr. Martin Hall for their comments and assistance. 


\begin{abstract}
THE INFLUENCE OF SPORTS PARTICPATION ON YOUTH BINGE DRINKING JASON NICHOLSON

May 1, 2017

This dissertation is an examination of the influence of sport participation on binge drinking among African-American youth. The dissertation is divided into five chapters, covering introduction, literature review, methodology, results, and conclusion. Chapter one describes the problem of binge drinking among African-American youth, focusing on the many deleterious consequences and rates of use. It also examines the problem theoretically through the criminological theories of social bond theory and social learning theory to argue for an understanding of binge drinking by African-American youth. Chapter two examines similar work by previous authors and further details our theoretical premises and their relation to substance use and sports participation by youth.
\end{abstract}

Chapter three describes the data, sample, coding of variables, and, analytic techniques that will be carried out. Specifically, a nationally representative sample of African-Americans were surveyed regarding their participation in various sports, demographic characteristics, and their experiences with school disciplinary practices. Through logistic regression analysis, these variables are expected to predict variation in binge drinking behaviors among African-American youth. Chapter four will describe the results of the data analysis. Chapter five links these anticipated findings to our theoretical premises and provides policy implications. 


\section{TABLE OF CONTENTS}

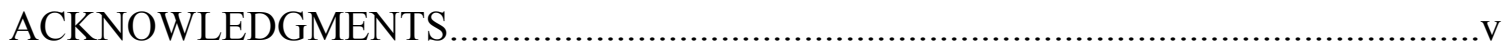

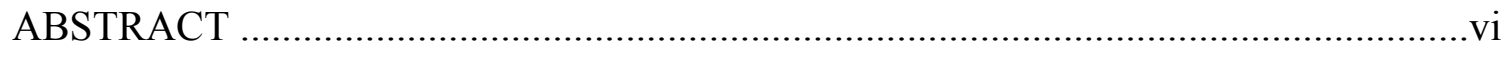

LIST OF TABLES ...........................................................

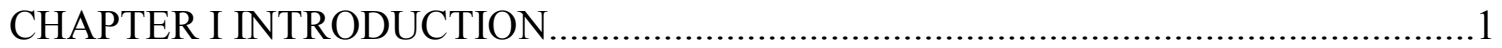

CHAPTER II LITERATURE REVIEW ................................................................. 14

CHAPTER III METHODS AND MATERIALS.......................................................49

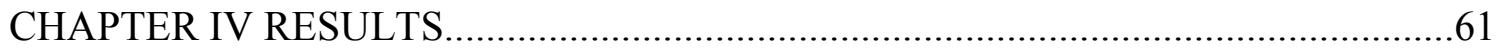

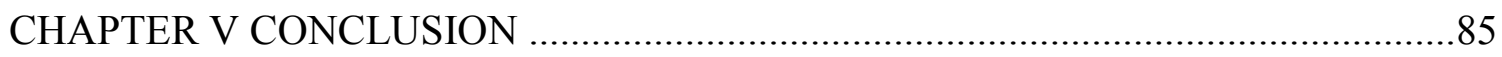

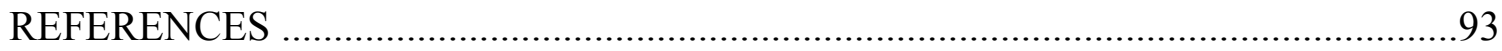

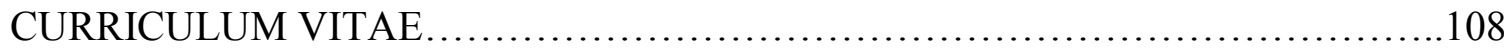




\section{LIST OF TABLES}

TABLE

PAGE

1. Descriptive Statistics Eighth and Tenth Grade Sample..............................63

2. Descriptive Statistics Twelfth Grade Sample....................................68

3. Tetrachoric Correlation Between Variables Eighth and Tenth Grade Sample................70

4. Tetrachoric Correlation Between Variables 12 grade sample ........................74

5. Logistic Regression Analysis Eighth and Tenth Grade Sample........................76

6. Logistic Regression Analysis Twelfth Grade Sample .............................. 77

7. Logistic Regression Analysis Eighth and Tenth Grade Males and Females ...................80

8. Logistic Regression Analysis Twelfth Grade Males and Females ..........................................83 


\section{CHAPTER I}

\section{INTRODUCTION}

Research has shown that alcohol use among adolescents was an important social problem. Binge drinking behavior has been shown to occur among adolescents and have a number of important health consequences. Some defined binge drinking as having 5 or more drinks in a row (A "drink" is a glass of wine, a bottle of beer, a wine cooler, a shot glass of liquor, a mixed drink, etc.) (Johnston, O’Malley, Bachman and Schullenberg, 2013). Specifically, binge drinking was known as the consumption of large amounts of alcohol in a short period of time. The definition of a large amount of alcohol has been subjected to debate (Dimeff, Kilmer, \& Marlatt 1995; Nelson, Naimi, Brewer \& Wechsler, 2005). Wechsler, Dowdall, Davenport, and Rimm (1995) provided a commonly used definition of binge drinking as consuming five or more drinks in an hour for men and four or more drinks in an hour for women.

Alcohol consumption has importance for the body. Specifically, alcohol consumption influences an individual's central nervous system. Alcohol consumption serves as a depressant to the body. Townshend and Duka (2005) showed that alcohol was a depressant and studied individual characteristics by comparing mood states and cognitive functions between binge and non-binge drinkers. To sample binge drinkers and a comparison group the highest and lowest 33.3 percent from a database of 245 drinkers from the Alcohol Use Questionnaire were taken. In other words, the Alcohol Use Questionnaire derives a binge drinking score based on a subject's drinking habits, with 
those in the highest 33.3 percent consuming the most alcohol (i.e., binge drinkers) and those in the lowest 33.3 percent consuming the least (i.e., non-binge drinkers). Their results indicated that binge drinkers had a less positive mood than the control sample. The bodily effects are also damaging in that alcohol, as a toxic chemical, must be flushed from the body placing increased strain on the liver and kidneys leading to cirrhosis and kidney disease (Rehm, Taylor, Mohapatra, Irving, Baliunas, Patra, \& Roerecke, 2010; Yamagata, Ishida, Sairenchi, Takahashi, Ohba, Shiigai, Narita, \& Koyama, 2007). These were not the only deleterious consequences that have been found. For example, binge drinkers were more likely to have unplanned and unsafe sexual activity, physical injuries, and physical and cognitive impairments (Cooper, 2002; Hingson, Heeren, Winter, \& Weschler 2005; Townshend \& Duka, 2005). Cooper (2002) reviewed literature that examined the association between drinking and risky sexual activity in a youth sample. Results showed that drinking was strongly related to the decision to have sex and many forms of risky sex including multiple partners, casual sex, and decreased protective behaviors. Beyond unsafe sex, Hingson, Heeren, Winter and Wechsler (2005) calculated the alcohol-related unintentional injuries, deaths, and other health problems among college students. The study utilized data from the National Highway Traffic Safety Administration, the Centers for Disease Control and Prevention, national coroner studies, census and college enrollment data for 18-24-year-olds, the National Household Survey on Drug Abuse, and the Harvard College Alcohol Survey in 1981 and 2001. During these years, the study estimated a 6 percent increase in deaths and health problems, an increase from 2.3 million to 2.8 million drunk drivers, and for both years 
more than 500,000 unintentional injuries and more than 600,000 hits/assaults by an intoxicated person.

Alcohol not only affects the binge drinker, but others as well. For those within the immediate environment of the binge drinker the secondhand effects have been problematic including: being insulted, physically assaulted, sexually assaulted, and having to aid drunk friends (Bouchery, Harwood, Sacks, Simon, \& Brewer, 2011). Bouchery, Harwood, Sacks, Simon, and Brewer (2011) found that the consequences of excessive drinking are thought to cost the economy an estimated $\$ 223.5$ billion with an estimated 76.4 percent being related to binge drinking. The study included the cost of hospitalization, health insurance administration, drugs and services to drinkers, prevention and research, ambulatory care, nursing home, crime victims, motor vehicle crashes, and lost productivity through mortality, incarceration, absenteeism, fetal alcohol syndrome, and impaired productivity.

The high binge drinking rates indicated the necessity for it to be studied. The National Survey of Drug Use and Health provides one estimate of the rates of binge drinking among youth of various social backgrounds. The NSDUH collects data from a nationally representative sample of American youth $(n=27630)$, including AfricanAmericans $(n=8561)$, regarding their substance use behaviors. Results have shown that 6.2 percent of all binge drinkers are in the 12 to 17 year old age group (SAMHSA, 2013). Generally speaking, studies have shown that 12 to 20 year olds consume 11 percent of all alcohol and more than 90 percent of their alcohol by binge drinking (Pacific Institute for Research and Evaluation [PIRS], 2005). Johnston, O’Malley, Bachman and Schulenberg 
(2013) found that 14.6 percent of students in the $8^{\text {th }}, 10^{\text {th }}$, and $12^{\text {th }}$ grades had selfreported being drunk.

Specifically among African-Americans, the 2012 NSDUH found that among African-American youth, from ages 12 to 20, 8.4 percent participated in binge drinking; binge drinking was defined as five or more drinks on the same occasion (SAMHSA, 2013). The same study identified that among African-Americans 12 to 17 years old in 2012, 9.3 percent reported the use of alcohol (SAMHSA, 2013). Wallace and Muroff (2002) found that African-American youth are at higher risk of exposure to risk factors of alcohol abuse and thus a higher vulnerability to alcohol use disorders. Data was taken from multiple years of the Monitoring the Future dataset $(n=49000)$. They found AfricanAmerican youth to be at higher risk of exposure and vulnerability to more than half of the 55 risk factors (e.g., peer association, favorable attitudes, alienation, low school commitment and involvement, parental supervision and conflict, economic deprivation, neighborhood deprivation) compared to whites.

Mulia, Greenefield, and Zemore (2009) reported that African-American youth were significantly more likely than white drinkers to experience negative social consequences and alcohol dependence symptoms from drinking. In other words, AfricanAmericans were experiencing higher frequencies of alcohol related problems at comparable levels of use when compared to whites. The study included data from the U.S. National Alcohol Survey $(\mathrm{n}=4080)$ with results having indicated that social disadvantage, specifically racial and ethnic stigma contributed to the higher rates of problems among African-Americans. 
Bradizza, Reifman, and Barnes (1999) studied race, gender, and age as

moderators of the social and coping motives behind alcohol misuse in black and white youth ( $\mathrm{n}=699)$ Interviews were carried out at six yearly intervals to gather information about drinking behaviors, psychological stress, and social and coping disorders. The motives of alcohol use among African-American adolescents were associated with the desire to regulate negative mood and cope with psychological distress.

\section{Sports Participation and Binge Drinking}

One lifestyle factor potentially associated with binge drinking by youth is athletic participation. There is extensive research connecting delinquency and extracurricular involvement such as sport participation (Eccles \& Barber, 1999; Fredricks \& Eccles, 2006; Hart \& Mueller, 2005). As such it is reasonable to believe that there could be an association between youth binge drinking and sports participation. Sport participation is significant to the adolescent culture in the United States with participation associated with increased social status (Holland \& Andre, 1994). Such salience has caused much debate about the social components of youth sports. Advocates for sport participation among youth have contended that interscholastic sports positively affect adolescent development. Several studies have shown sport participation to be linked to a variety of benefits including higher self-esteem, discipline, educational achievement, and prosocial behavior including reduced substance use (Eccles \& Barber 1999; Fejgin, 1994; Mahoney \& Cairns 1997; Marsh 1993; McNeal, 1995; Otto \& Alwin 1977). Those critical of the effect of sport participation on youth, however, have found other more problematic results involving sport's underlying contradictions with positive social development. Critical scholars have found the culture of sport participation to perpetuate delinquent 
values among youth including inequality, aggression, mental health problems, and increased substance use that includes binge drinking (Gatz, Messner, \& Ball-Rokeach 2002; Heyman, 1986). Athlete status has been found related to alcohol related problems including hangovers, academic problems, relationship problems, criminal perpetuation and victimization, injuries, and unsafe or unplanned sex (Martens, Cox, \& Beck, 2003; Nelson \& Wechsler, 2001).

Specifically, this dissertation will focus on the effect of sport participation on delinquency and development in the form of binge drinking by youth. As previously indicated, research results were mixed regarding the effect of sports participation on youth substance use (Denham, 2011; Eccles \& Barber 1999). Some have found a protective effect in that sport participation is associated with fewer instances of substance use (Penerson, Poulin, Lefcoe, Donald \& Hill, 1992). Pederson, Poulin, Lefcoe, Donald, and Hill (1992) found that through improved social bonds and the immediate deleterious effects of recreational drug use on athletic performance, sport participation controlled such problematic behaviors among youth.

This finding, however, was not universal as research involving other samples have found that athletes of various sports used and abused illicit substances more than non-athletes (Denham, 2011; Eitle, Turner, \& Mcnulty-Eitle, 2000; Ewing, 1998; Stogner \& Miller, 2013). Eitle, Turner, and Mcnulty-Eitle (2003) challenged the widely held belief that sport participation lowers the risk for substance use. Their longitudinal study involved a nationally representative sample of preteens through young adulthood. The study contained many control variables related to substance use risk. Results revealed that contrary to the deterrence hypothesis, playing sports did not appear to prevent 
alcohol or drug use in young adulthood. In other words, playing high school sports was positively associated with greater alcohol use, even when controlling for other strong predictors of alcohol use (e.g., stress exposure, socioeconomic status, family structure, and peer substance use).

Furthermore, research had shown that alcohol use did not necessarily jeopardize athletic performance. Denham (2011) found that youth participating in baseball, football, and weightlifting, which some call power sports (Kreager, 2007), had higher levels of alcohol consumption compared to their nonparticipating peers. Denham (2011) suggested that this higher likelihood of consuming alcohol is due to how these sports involved anaerobic conditioning (short bursts of strength), which would be related to a belief that athletic performance would not be jeopardized by alcohol consumption.

Sport participation could be associated with alcohol use, specifically binge drinking, for a number of other reasons. Heyman (1986) found that the high demands of multiple obligations (classes, practices, training, and social life) can be overwhelming and lead to developmental, emotional, and psychological disorders for athletes. These activities could wither positive environments that have been developed weakening bonds to the teams and schools. Further, peers on these teams might provide a substantial amount of influence for binge drinking. Those more heavily involved and invested in their sport have been might be more likely to engage in binge drinking then those less involved (Hildebrand, Johnson, \& Bogle, 2001).

Athletes have also been encouraged or pressured into binge drinking by environmental and cultural influences. Robinson (1998) pointed out the media's extensive coverage of professional athletes, often role models for youth, included their 
numerous arrests for substance use. Athletes have been found to associate most with their teammates (Thombs \& Hamilton, 2002) who can be pushing undesirable pro-drug social norms. Dams-O'Connor, Martin and Martens (2007) found that_perceptions of a group's social norms can predict personal levels of drug use.

\section{Theoretical Perspective}

To contextualize the understanding of sport participation and substance use, two criminological theories could be used to contextualize binge drinking by youth that participate in sports - social bond theory (Hirschi, 1969) and social learning theory (Akers, 1998). Hirschi (1969) contended that integration into social groups, like sports teams, can create influences and pressures on a person to accept and conform to the larger group's norms and behavioral expectations. While social learning theory (Akers, 1998) describes how behaviors, deviant or conforming, can be learned from others through social interactions.

Briefly, Hirschi’s (1969) social bond theory held four main components including: (1) attachment, (2) involvement, (3) commitment, and (4) belief. Hirschi (1969) described attachment as having a strong emotional connection to the group that influences a youth's behavior due to the desire for the group's approval. When attachment to the group is strong, a youth will be led to care about group member's opinions. A youth will not want to do anything that will disappoint or lose respect from those to whom they are attached. Another bond, involvement, revolved around the idea that the more time that is spent in conventional activities was inversely related to the time available for delinquent activities. Thus, youth who are involved in more structured and conventional activities will be less delinquent. With the third bond, commitment, Hirschi 
(1969) referred to an individual's stake in conformity to the group's norms or the investment they have made towards group affiliation. If much effort has been invested into gaining approval from a social group than an individual will avoid activities that will jeopardize social standing within the group. The final bond, belief, involved the acceptance of the moral validity of the group's norms. (Hirschi, 1969). Those who embraced the conventional norms or were encouraged by group members will behave accordingly. Norm violation occurred when beliefs in a group's moral order were weakened.

Through these four components, a bond is established between a juvenile and a peer group. Groups that emphasized positive social behaviors will contribute to the development of these behaviors in those that enter and conform to the group. On the other hand, groups that emphasized delinquency will encourage these behaviors into individuals as conformity grows. The theory contended that the deviant aspects of a group's behavior are overlooked because of the individual's bonds to the group. Studies on gang influences in high school settings have been supportive of this theory (Estrada, Gilreath, Astor, \& Benbenishty, 2014).

Turning now to social learning theory, Akers (1998) described a process of how deviant behaviors are learned through social interaction with others. Through the four main components (differential association, definitions, differential reinforcement, and imitation) deviant behaviors witnessed in one person can be learned by others. Differential association referred to social interactions between individuals such as peer groups, students and teachers, or family members. Akers (1998) considered these interactions vital as they exposed an individual to behavioral models. 
Definitions are known as the beliefs and attitudes that individuals associate with certain behaviors. Akers' (1998) conception of beliefs included the rationalizations, orientations, and justifications that make an act delinquent or conforming. Differential reinforcement is the anticipated or actual positive (rewards) or negative (punishment) stimuli (Akers, 1998). In other words, the choice to engage in a particular behavior is influenced by anticipated desirable or undesirable outcomes.

The last component of social learning (Akers, 1998) is imitation, or the modeling of behaviors that an individual observed in others. Imitation led to new behaviors through the vicarious observations of the behaviors of others and the consequences that follow. For instance, some may be encouraged to participate in a behavior after witnessing another's participation and recognizing their rewards or lack of punishment. The probability of an observed behavior being imitated is related to characteristics of the model and the observed behavior in question. Akers (1998) contended that when the behavior and observer are in direct contact the likelihood of imitation is greater.

These theoretical perspectives have been vital to our understanding of delinquency with many studies having found a link between social bond and social learning concepts and substance use that included binge drinking (Bahr, Hoffman, \& Yang, 2005; Burton, Florell, \& Wygant, 2012; Henry \& Slater, 2007; Hoeve, Stams, and Van der Put, Dubas, Van Der Laan \& Gerris, 2012). Further, the current dissertation's focus of youth sport participation has been found to be relevant to the social bond (Hirschi, 1969) and social learning (Akers, 1998) perspectives. Sport participation, as studied through the lens of social bond (Hirschi, 1969) and social learning (Akers, 1998), has been found to be a mediating factor in youth's conforming and delinquent behavior 
(Ecceles \& Barber, 1999; Marsh \& Kleitman, 2003; Miller, Melnick, Barnes, Sabo, \& Farrell, 2007).

More specifically, in terms of social bonds, sport participation has been found to be one of the factors that has contributed to the relationship between school belongingness, connectedness, attachment, and delinquency with research results having indicated that sport participation increased commitment and identification to school and liking school (Ecceles \& Barber, 1999; Marsh \& Kleitman, 2003). Marsh and Kleitman (2003) found that participation in high school sports had many positive effects during the senior year of high school and postsecondary results. After controlling for background characteristics school-based sport participation had significant effects on 13 of the 21 secondary and post-secondary outcomes. Sports participating students were, for example, more involved with homework, applied to more universities, had higher parental expectations, had higher grades, higher self-esteem, and higher educational aspirations. Thus, sport participation can be seen as related to social bond theory (Hirschi, 1969) due to the controlling effect on delinquent behavior.

Similarly, Veliz and Shakib (2012) found that schools with higher percentage of students-athletes also had fewer reports of serious crimes. Their study involved social control and cultural spillover theories to explain the link between sports programs and school environments with a nationally represented sample of public school students $(n=1200)$. Results indicated that schools with greater ratios of sport participants contained significantly fewer violent crimes and disciplinary actions (suspensions). However, mixed and opposite results exist in that sports participation has been found to be not related to social bonds or decreased criminality (Miller et al., 2007). 
In terms of social learning theory (Akers, 1998), previous research has shown ways in which sport participation has served as a gateway for youth to be exposed to delinquent behaviors that can be learned (Kreager, 2007). Kreager (2007) applied the social learning and social bond premises to sport participation and violence. With data from the National Longitudinal Study of Adolescent Health $(n=20,745)$ Kreager (2007) studied how type of sport and peer athletic participation contributed to violence. Results indicated a strong relationship between contact sports and violence; participants in football and wrestling were more likely to engage infighting than those involved in baseball, basketball, tennis, and other athletes.

In conclusion, binge drinking was shown to be a social problem with adverse health effects for multiple individuals (Cooper, 2002; Hingson et al., 2005; Townshend \& Duka 2005; Gogtay, Giedd, Lusk, Hayashi, Greenstien, Vaituzis \& Thompson, 2004; Gruber, Pope, Hudson \& Yurgelun-Todd, 2003). Importantly, studies showed that binge drinking was common among juveniles and African-Americans (Johnston, et al., 2013; SAMHSA, 2013). Two criminological theories that aid in our understanding of youth substance use include social bond (Hirschi, 1969) and social learning (Akers, 1998). These theories have been important in contextualizing our understanding of delinquency and were highly relevant to youth sport participation's effect on delinquency including binge drinking (Ecceles \& Barber, 1999; Kreager, 2007; Marsh \& Kleitman, 2003). The issue with these literatures is that no study has examined an all-African-American sample to understand the link between different types of sports and binge drinking in the context of social bonding and social learning theory.

\section{Purpose}


The purpose of this dissertation is to assess the effect of participating in different types of sports on youth binge drinking among African-Americans. The current dissertation contains two hypotheses. Hypothesis 1: The type of sport that an individual participates in would provide a difference in binge drinking among African-Americans. Hypothesis 2: Consistent with the literature (Endresen \& Olweus, 2005; Kreager, 2007, McCauley et al., 2014) power sport participation would result in African-American youth binge drinking. Hirschi's (1969) social bonding theory and Akers' (1998) social learning theory were used to contextualize the results of this study. In other words, an individual's integration into social groups, such as sports teams, including their norms, activities, and peer influences make social bond (Hirschi, 1969) and social learning theory (Akers, 1998) ideally suited for the current dissertation. Hypothesis 3 the effect of sport participation on binge drinking will be moderated by gender.

Chapter 2 will further explore the current dissertation's theoretical framework including social bond (Hirschi, 1969) and social learning (Akers, 1998) and apply the literature on sports participation and binge drinking within this context of AfricanAmericans. Chapter 3 describes the data and methodology utilized by this study. Chapter 4 explains the results of the analysis including descriptive statistics and logistic regression analysis. Last, chapter 5 will discuss the findings of our analysis in the context of our theoretical framework, discuss the study's limitations, implications for policy, and directions for future research. 


\section{CHAPTER II}

\section{LITERATURE REVIEW}

Chapter one described the problem of African-American youth binge drinking for the purpose of this dissertation. Also, discussed was the potential effect of sports participation on a youth's decision to engage in substance use. This chapter details the theoretical framework of the social bond and social learning premises and their contribution to the connection between sports participation and delinquency. Also included is literature on previous studies related to sports participation and delinquency.

\section{Social Bond Theory}

Hirschi (1969) argued out his social bond theory in Causes of Delinquency. Categorized as a control theory, Hirschi (1969) assumed that delinquency is normal and that all individuals are predisposed to criminality. Hirschi (1969), rather, sought out to explain conformist behaviors through his four social bonds. Hirschi (1969) theorized that when social bonds are weak or absent this allows delinquent behavior to occur. Hirschi (1969) proposed that individuals are restrained from their predisposition to delinquency because they are bonded to society. These four bonds were (1) attachment, (2) commitment, (3) involvement, (4) and belief.

\section{Attachment}

The first of the social bonds was attachment, which involved the value that an individual places on other people's approval of their behavior (Hirschi, 1969). 
Attachment involved the amount of affection and respect that the individual had for significant life figures such as parents and teachers. Individuals were less likely to engage in delinquency when accounting for how such behavior would affect a role model's or significant figure's opinion of them. As detailed by Hirschi (1969) "to lack attachment to others is to be free from moral restraints is to use lack of attachment to explain the guiltlessness of the psychopath, the fact that he apparently has no conscience or superego" (p. 18). The person with weak attachment was more inclined to delinquency because they feared remorse for acting contrary to the wishes of significant others. Hirschi (1969) described this bond of attachment could come in the form of attachment to parents or schools.

Attachment could come in many forms. Hirschi (1969) believed an important source of bonding was between the youth and the parent. Hirschi (1969) contended that strength of the attachment, in the form of affection, intimacy, sharing, agreement, and frequent communication the lesser the chances of delinquency. The bond of attachment to parents also held the concept of direct versus indirect control. Direct control was the idea that when in direct contact with, parents and their children for example, children respond with good behavior as the consequences of delinquency in the sight of their parents were probable. In contrast, indirect control referred to how children retain good behavior even when not in the direct presence of their parents due to the lingering sense of attachment and desire to not disappoint their parents.

Beyond attachment to parents, Hirschi (1969) believed that the school provided youth another source of prosocial attachment. In terms of school bonding, Hirschi (1969) contended that youth who did not care about making good grades, what their teachers 
thought about them, and did not spend much time on homework were more inclined to delinquency. Youth who did not have high goals for the future, and generally wished they did not have to go to school were the youths most likely to be engaged in delinquency.

Hirschi (1969) also viewed a youth's level of attachment as fluctuating beside the level of accomplishment by students. Hirschi (1969) believed that those who performed better in school would gain rewards and recognition for their achievements. While those who performed poorly were not rewarded as the academically superior students, which thus lowered attachment to schools. Attachment was one form of social bonding. Commitment is another form of social bonding.

\section{Commitment}

The second of Hirschi's (1969) social bonds, commitment, was defined as an investment towards or stake in conformity towards conventional society. The commitment bond involved everything that a person would stand to lose by engaging in delinquency including investments made towards prosocial pursuits. Delinquency could limit opportunities towards or reverse investments of time and energy in achieving tangible and intangible benefits such as education, status, money, or employment (Hirschi, 1969).

Hirschi (1969) described the commitment bond as involving rational thought. A cost benefit calculation was conducted, consciously or subconsciously, by individuals regarding the value of their stake in conformity and risk faced by losing such commitment before committing delinquency. The individual, also, needed to analyze the probability of being reprimanded for committing delinquent acts in order to guard against 
negating heavy efforts towards conformity. Hirschi (1969) argued that some aspects of life that held potential for high levels of commitment included education, occupation, and passage to adult status. Achieving an education and starting a career were seen as signs of passage into life as a responsible adult and thus highly valuable to youth.

Students, as an example, who were expected to go to college were thought to be less delinquent because individuals who commit deviant acts jeopardize their chances of future success. Hirschi (1969) contended delinquents did not worry about the consequences of delinquent behavior due to their loss of motivation to attain such adult status as education and a highly respected career. Hirschi (1969), further, proposed that youth whose career prospects were limited compensated for this weakness by participating in other adult-like activities such as drinking, smoking, and sexual activity.

\section{Belief}

The third component of the social bond was belief. Hirschi (1969) argued that belief pertained to the level of agreement an individual applied to the rules of society and the extent to which a person felt they should obey the dominant norms of society. According to assumptions of control theory, delinquency was not due to a belief in a delinquent subculture, instead it was the lack of belief in the norms of society. Hirschi (1969) described this bond as the individual's commitment to the "central social-value system" (Hirschi, 1969, p. 203). Agreement to conventional values would reduce the likelihood of engaging in delinquency, but lacking agreement with and belief in the society's conventional values system raised an individual's propensity to engage in delinquency (Hirschi, 1969). 


\section{Involvement}

The final component of social bond theory was involvement. Hirschi (1969) stated "of the elements of the bond to conventional society, involvement in conventional activities is most obviously relevant to delinquent behavior" (p. 187). This bond was related to the concept "idle hands are the devils workshop." In other words, a lack of structured activities to keep youth busy provided an opportunity for delinquency and more time that was spent in conventional activities such as sports, clubs, studying, the more this problem of idle hands was prevented. The time spent on conventional activities was inversely related to delinquency in that conventional activities take up the time that could otherwise be spent in delinquent activities. Thus, someone engaged in much conventional involvement would be less likely to be engaged in delinquency. This supports the notion that youth sport participation is a positive pursuit that would limit a youth's potential to engage in delinquency.

In summary, Hirschi's (1969) social bond theory included four bonds to society that when present or strong prevented delinquent behavior. These four bonds were attachment, commitment, involvement, and belief (Hirschi, 1969). Hirschi (1969) social bond theory has been subjected to much empirical research. The next section will summarize this empirical support for the theory.

\section{Empirical Support for Social Bond Theory}

Several empirical studies have supported each of the four social bonds as being associated with lower levels of delinquency (Hirschi, 1969; Hoeve, et al, 2012; Huebner \& Betts, 2002). Hirschi (1969) included an empirical analysis of his four social bonds in Causes of Delinquency. Hirschi (1969) found support for his attachment premise in 
analyzing youths' amount of shared thoughts and feelings with parents, parental monitoring, agreement with parents, admiration of parents, and parental helpfulness and finding significant correlations to lesser levels of delinquency. In other words, youth whose parents, frequently, knew where they were, talked to their parents, and positively identified with their parents were less likely to be delinquent (Hirshi, 1969).

Beyond their parents, schools were also a source of attachment for youth. The concept of non-delinquent youth that were attached to schools gained some support in Hirschi's (1969) analysis with delinquents more likely to report themselves as below average students than non-delinquent youth. Furthermore, Hirschi (1969) analyzed youth's attachment to school and found a significant correlation with delinquency in that youth who disliked school, devalued teachers opinions of them, and did not approve of school authority were more likely to be delinquent. Hirschi (1969) examined the strength of school bonding variables (academic performance, liking school, caring about teacher's opinions, and school authority) and found that attachment to school accounted for more variance in delinquency than parental attachment.

Regarding the commitment bond, Hirschi's (1969) views on commitment were confirmed by his data analysis from which results indicated that the less education the youth anticipated attaining the greater their probability of smoking, dating, and drinking. Hirschi (1969) also noted that delinquents had more spare time available to them. For example, findings showed that youth who more often experienced boredom had more occurrences of delinquency. Boredom was also inversely related to the time spent on homework each day. Hirschi (1969) also assessed the relation between involvement and time spent with peer groups. Having more free time was likely related to spending more 
time with friends. Analysis showed that youth who spent more time with friends were more than twice as likely to have committed delinquent acts as youth who did not. Data analysis also showed that time spent with friends could influence delinquency regardless of time spent in school-related involvement. A final note was that Hirschi (1969) also concluded empirically that delinquent youth who were more bored, despite high levels of school involvement and commitment, engaged in more delinquency that youth who did not spend time with friends or report boredom.

Regarding involvement, Hirschi (1969) believed one of the biggest sources of involvement was involvement in school. Hirschi (1969) analyzed the amount of time youth spent doing homework and found a strong negative correlation between time spent doing homework and delinquent acts committed. He recognized that time spent on homework could be related to academic performance and analyzed time spent doing homework and average grades and found that homework was related to delinquency according to all performance levels.

Moving on to the social bond of belief, Hirschi (1969) assessed the bond of belief in regards to youth's respect for authority figures (parents and police officers) and attitudes towards the law in general. Specifically, Hirschi (1969) also believed that attachment to parents was the origin of respect for the rules of society and authority figures. Hirschi (1969) contended youth who were less attached to their parents or who were less concerned about their parent's approval would hold weak ties to authority figures. As related to self-reported delinquency, Hirschi (1969) found the belief component to be one of the strongest predictors. On one hand, youth who valued their parents opinions, respected the police, acknowledged the legitimacy of rules and laws 
were less likely to engage in delinquency. On the other hand, youth who had little communication with their parents, did not respect police, and did not recognize the authority of societal rules were more likely to engage in delinquent acts.

Beyond Hirschi’s (1969) own analysis, scholars have found support for the social bonding theory. Hart and Mueller (2012) studied school misconduct and social bonds in a sample of $1175810^{\text {th }}$ graders. Included in the analysis was parental involvement, bonds to school, commitment to sport and non-sport activities, and the importance of student beliefs in frequently held social norms on school delinquency. Regression results indicated that the all of the social bond components were significantly and negatively related to delinquency. The study also included a gendered analysis, which revealed gender to be a mediator between social bonds and school delinquency. Stewart (2003) examined the extent to which individual and school-level factors explained variation in misbehavior among a nationally representative sample of high school students $(n=10,578)$. Data analysis indicated that higher levels of school attachment, school commitment, and belief in school rules were significantly related to lower levels of misbehavior in school. Li (2004) examined social bonds in a nationally representative sample of 4866 American youth. Control variables included race, gender, delinquent association, and illegitimate opportunities. Results found crime to be negatively correlated with the four elements of social bond including attachment, commitment, involvement, and belief.

Several studies have included tests of the individual components of social bond on general delinquency with promising results. Even among special populations that are more prone to delinquency such as abuse victims (Ryan \& Testa, 2005), high levels of 
attachment and commitment have been shown to be an inhibitor to unconventional activities. Ryan, Testa, and Zhai (2008) studied juvenile delinquency within the child welfare system. Delinquency was examined through commitment to education, church, and foster parents. The sample was 278 youth between 11 and 16 years old within foster care. Results indicated that the various measurements of commitment with a religious organization and foster-parent attachment decreased the likelihood of delinquency for the sample. Those with prior school suspensions were also more likely to engage in delinquency, lending itself to the school commitment premise.

Further, Johnson, Jang, Larson, and Li (2006) tested religious commitment with data from the National Youth Survey, a longitudinal nationally representative probability sample ( $\mathrm{n}=1725)$ of American youth ages 11 to 17 . They hypothesized that religious commitment mattered with regard to behavioral problems through the lens of Hirschi's (1969) social bond theory. Results showed religious commitment to be highly related to a variety of delinquent acts in the anticipated direction.

Menasco (2005) examined social bonds, adolescent delinquency, and academic performance in a comparison of the sexes. The study utilized a large dataset of 8363 youths from the 1990 and 2000 waves of the National Education Longitudinal Study findings provided partial support for social bond theory and a differentiating effect across the sexes. The bond of belief stood out as the only bond to have a significant and negative relationship to all forms of delinquency for both sexes.

Other scholars have found involvement to be related to delinquency as well (Huebner \& Betts, 2002). Huebner and Betts (2002) studied the attachment and involvement bond according to gender differences in predicting delinquency and school 
achievement. Surveys were administered to a sample of $7^{\text {th }}$ and $12^{\text {th }}$ graders $(\mathrm{n}=911)$. Only the involvement variables were significantly and negatively related to delinquency for both genders. Involvement included high levels of studying, doing chores, hobbies, and after school activities.

However, involvement had been criticized as being least important of the bonds because of weak or insignificant results (Jenkins, 1997; Junger \& Marshall, 1997; Leonard \& Decker, 1994). Jenkins (1997) surveyed $7547^{\text {th }}$ and $8^{\text {th }}$ grade students regarding their levels of involvement as related to delinquency. Results from the study indicated that of the four components of social bond theory certain components were more important than others were. Specifically the study's measures of the bonds of belief and commitment had a significant and negative impact on delinquency; the study's measures of the bonds of attachment and involvement were not significant predictors. In terms of school misconduct, the study's measure of involvement was the only bond that failed to be a significant predictor.

Leonard and Decker (1994) studied social bonds and delinquency among $5^{\text {th }}$ graders. The study concluded that the involvement element of social bond was inversely correlated to nonconformity for males but positively related to exposure to drugs, especially for African-American youth and failed to reach significance for any other measure.

Krohn and Massey (1980) noted how involvement and commitment share similarities and that individuals will not invest in activities to which they are not committed. Due to this weak relationship between involvement and delinquency, some researchers elected to not include involvement measures in their theoretical models 
(Dukes, Martinez, \& Stein, 1997; Heimer \& Matsueda, 1994; Seydlitz, 1993). The possibility also exists that the bonds alone can have weak relationships with delinquency but when considered in tandem the four bonds together may provide a strong link

Wiatroski, Griswold, and Roberts (1981) found this to be true as the bonds being considered together provided more significance than any on their own. Hirschi (1969) stated "In theoretical statements, in practical programs, and in the common sense, the idea of involvement remains central to much thinking about the causation and prevention of delinquency" (p. 188). Hirschi (1969) has also contended that research shows weaknesses with the involvement hypothesis because it can be hard to distinguish measures of involvement from the other social bonds.

The social bonding research has not been a general body of work. Some scholars have examined the theory using exclusively minority populations. One minority population that has received some attention is African-Americans. D'Apolito and Wantatah (1998) found that differences in the strength of social bond predictor variables varied by race. In their sample of 172 seventh and eighth grade male students in an Eastern Ohio urban school system, they performed path analysis for African-American and white youth in the context of juvenile male violence. For the African-American sample, parental rejection was found to be the strongest predictor of juvenile male violence, while this was not a significant predictor of violence among whites. Furthermore, their model explained more of the variance in violence for the AfricanAmerican sample than for the whites.

For African-American youth, school social bonds have been shown to have distinctive patterns. In the context of schools, studies showed that ethnic minorities 
reported lower attachment to school (Cheng \& Klugman 2010; Johnson et al. 2001; Ueno 2009). Abbey, Jacques, Hayman, and Sobeck (2006) found that school commitment helped control deviant behavior among African-American youth in urban and suburban communities. Scholars showed that minority, including African-American, adolescents involvement in extracurricular activities minimized delinquent participation and dropout rates (Peguero, Pop, \& Lattimore, 2011; Feldman \& Matjasko 2005, 2007; Fredericks \& Eccles, 2006; Okamoto, Herda, \& Hartzog 2013). In terms of belief, scholars showed African-Americans had less belief that school rules and policies are fair and just (Peguero 2012; Cammarota, 2004; Hagan, Shed, \& Payne, 2005).

Researchers performed several meta-analytic reviews and reviews of the literature of social bonding theory and general delinquency. Kempf (1993) found belief to be the most consistent and robust predictor of delinquency in the studying empirical status of social bond theory in the literature review from 1973-1990. In a meta-analysis, Hoeve, Stams, and Van der Put, Dubas, Van Der Laan and Gerris (2012) conducted a multi-level meta-analysis of 74 manuscripts related to parental attachment and delinquency in the context of social bonding. Selection of studies was based on such criteria as: delinquency defined as behavior prohibited by law, focusing on quality of relationships, the bond to parents, or affectional identification, toward the parent, sample participants were from western countries and the study must include the results of bivariate analysis of the association between attachment and delinquency (Stams, Van der Put, Dubas, Van Der Laan, \& Gerris, 2012). Findings were examined from the perspective of social control and attachment theories with poor attachment to parents being significantly associated with delinquency for both boys and girls. 
In summary, much empirical support exists for Hirschi's (1969) version of social bond theory. Specifically, his contentions that worn or broken attachment, commitment, involvement or belief was associated with general delinquency (Hirschi, 1969; Ryan, Tests, \& Zhai, 2008; Wiatroski, Griswold, and Roberts, 1981). Distinctions in social bonding in exclusively African-American and minority populations have been found as well with relation to delinquency as anticipated (Abbey, Jacques, Haymen, \& Sobeck, 2006; Peguero 2012; Peguero et al. 2011). For the purposes of this dissertation, it was important to note that social bond theory (Hirschi, 1969) had relevance for sport participation.

\section{Social Bond and Sport Participation}

Scholars used social bonding theory as a context to examine the link between sport participation a myriad of behaviors. Some of these behaviors were deviant (Crosnoe 2001; Larson 1994; McNeal 1995) and others were prosocial. As noted, instead of a focus on delinquent motivations, Hirschi's (1969) social bond theory contended that variations in delinquency were due to the weakening or absence of restraining influences such as attachment, commitment, involvement, and belief. Schools and the potential positive relationships within could provide students with important places for youth to form these positive bonds that could reduce instances of delinquency (Hirschi, 1969).

School sport participation has been found to be a pathway to youth forming social bonds that could, potentially, reduce instances of delinquency (Crosnoe 2001; Larson 1994; McNeal 1995). First, sports participation could increase attachment through positive interactions with administration, teammates, fans, and coaches (Booth, Farrell, \& Verano, 2008). These strong positive ties might decrease the likelihood of delinquency by 
providing the individual with sets of significant others whose opinions were, likely, to be important to that individual. Agnew and Petersen (1989) recognized that, "engaging in pleasurable leisure activities with parents will increase the adolescent's level of attachment to parents, which is then assumed to reduce delinquency" (p. 333). Second, sports participation should develop youth's level of commitment to conformity, as consequences for deviance would result in the loss of further athletic participation and a reduction in social status among peers. Furthermore, athletic participation provides the opportunity for educational advancement in the form of college scholarships, a goal to which can become highly committed. Third, the time investment related to sports participation was high and disrupted the amount of time left for delinquent activities (McNeal, 1995). Finally, with the rules and value systems of sports being reflective of the values of greater conventional society, sports participation should raise a youth's belief in the validity of the dominant moral order, and therefore conventional prosocial behavior (Larson, 1994).

The contention that sport participation could strengthen a youth social bonds and reduced the likelihood of delinquent behavior has been supported by empirical research. Athletic participation had been found to increase attachment to peers and schools (Eccles \& Barber, 1999; Juvonen, Espinoza, \& Knifsend, 2012), and sport participation raised levels of prosocial involvement (Sandford, Armour \& Washington, 2006). Studies showed that athletes were often highly committed to their sports and were more likely to turn down delinquent opportunities (Eccles \& Barber, 1999). Further, McNeal (1995) found that participation in the fine arts and athletics significantly reduced a child's chances of dropping out of school, while participation in academic or vocational clubs 
had no effect. When all of these activities were examined together, only athletic participation had a significant effect on reducing dropouts. Further, athletics and fine arts were found to be key intervening variables intensifying the direct relationship between demographics such as race gender, academic ability, and dropouts. These findings remained after controlling for forces thought to be related to dropout such as socioeconomic status and employment.

In addition, Mahoney (2000) conducted a longitudinal study with 695 participants interviewed annually from childhood until the $12^{\text {th }}$ grade and finally at ages 20 and 24 . Cluster analysis established four configurations of youth in terms of behavior and academic performance. When the study continued overtime, the configurations differed in terms of early school dropout and criminality. Those in the multiple risk configuration were more likely than those in other configurations to have long-term antisocial behavioral patterns. Participation in school extracurricular activities, including sports, was related to lesser rates of early dropout and criminal arrest among the high-risk group. This reduction in antisocial patterns was dependent on the youth's social network also participating in extracurricular activities. Positive results from extracurricular activities were found for both genders.

Langbein and Bess (2002) suggested policy implications related to school sport participation to help control delinquency. They studied the relationship between school disturbances and the presence of interscholastic sports programs in High Schools of Montgomery County, Maryland. With years of data from high schools within the county, the study used sports participation, demographic variables, school size, and a dummy code for each school to predict school disturbances. Results indicated that larger schools 
had more disturbances but bigger interscholastic sports programs mitigated these effects. The study was examined through the lens of social capital theory, which, similar to social bond (Hirschi, 1969), predicted that group cohesion will increase cooperative, prosocial behavior among group members. However, social capital theory predicted an increase in delinquency among those not in the group especially when group membership is desirable. The research to this point indicated that social bonds were plausible in explaining the prosocial behavior that comes from sport participation.

Unfortunately, not all of the social bonding that comes from sport participation resulted in prosocial behavior. Kreager (2007) showed the assimilation into sports teams and their collective beliefs, when delinquent, had a relationship to greater levels of delinquency. In other words, Kreager (2007) showed that sport participation provided an environment where the bonds to prosocial norms, and not necessarily the informal norms of the sports team, were weakened or broken allowing delinquency to occur. Further, Kreager (2007) found this perspective to be most common among power sports that included the following: football, wrestling, and etc. Kreager (2007) contended that this finding emphasized peer contexts as an important mediator in anti-social behavior.

Kreager (2007) was not the only researcher to make this discovery. Endresen and Olweus (2005) found similar results and contended that participation in power sports led to an increase or enhancement of antisocial behavior, which they name the "enhancement hypothesis". More specifically, they studied a sample of 477 boys, aged 11 to 13 in a longitudinal design involving different participation patterns over time that allowed for study of the possible casual effects of power sports (i.e., boxing, wrestling, weightlifting, martial arts). Their dependent variable included levels of violent (e.g., using physical 
force to inflict injury or discomfort, started a fight with another student, hurt somebody in a fight with a weapon) as well as nonviolent antisocial behavior (e.g., vandalism, theft, truancy) outside of sports.

Ecceles and Barber (1999) examined how participation in five types of prosocial activities, including sports participation was linked to positive and negative development. Participation in all five of these activities provided a protective effect regarding both academic performance and involvement in risky behaviors. Specifically, with sport participation, involvement increased the likelihood of attending a four-year university and predicted increases in school attachment. However, sport participation was linked to an increase in binge drinking behaviors. This suggested that additional socialization may be taking place in sport participation that results in delinquent behavior.

Mahoney and Cairns (1997) conducted a longitudinal assessment of 392 adolescents in the $7^{\text {th }}$ grade annually through the $12^{\text {th }}$ grade. Findings showed that school dropout (defined as failure to complete the $11^{\text {th }}$ grade) among at-risk students was lower for students who participated in extracurricular activities, including sports, than those who did not participate. However, extracurricular involvement that included sport participation had a lesser effect on school dropout among students determined to be competent or highly competent during middle school.

However, opposite results also exist in analyzing sport participation through social bond theory (Hart \& Mueller, 2012; Kreager, 2007). Hart and Mueller (2012) analyzed commitment to sport participation as related to delinquency (being late for school, cutting or skipping classes, being absent from school, not following rules, inschool suspensions, suspended or put on probation, transferred for disciplinary reasons). 
They considered the influence of the strength of the engagement youth possessed towards school sponsored sport activities and non-sport activities.

Sport activities included in baseball, softball, basketball, football, soccer, or other team sport and individual sports such as cheerleading pompon or drill team.

Commitment to non-sport activities included participation in band, orchestra, chorus, choir, school plays or musicals, student government, academic honor societies, yearbook, newspaper, literary magazine, service club, hobby club, and vocational training club. Regression results revealed that commitment to sport activities was significantly and positivity associated with delinquency while commitment to non-sport activity was significantly and negatively associated with delinquency.

Miller, Melnick, Barnes, Sabo, and Farrell (2007) studied sports participation and delinquency through social bond theory with a general hypothesis that sport participation provided youth opportunities to build character, structure adolescents time, incentives to socially approved behaviors, and contact with positive role models. The sample included approximately 600 youth from western New York. Contrary to the assumptions from social bond theory (Hirschi, 1969), no deterrent effect was found regarding sports participation on minor or major forms of delinquency. Miller et al. (2007) concluded that either sports participation did not reliably strengthen social bonds or the effect was offset by other factors, for example positive deviance (Hughes \& Coakley, 1991).

Little research has been performed that examined the link between sport participation and delinquency using Hirschi's (1969) as the context among AfricanAmerican samples. Jordan (1999) presented the only study that attempted to contribute to this literature. Jordan's (1999) study showed that sport participation improved school 
engagement (i.e., prosocial behavior). The problem with Jordan's study was it did not consider delinquency as a possibility. With only one study in the empirical literature, the possibility does exist that additional research will uncover a link between sport participation and delinquency in the context of Hirschi's (1969) social bonding theory among African-Americans. Delinquency was not focus of this dissertation, but substance use was the focus of the dissertation. Next, the link between social bonds, sport participation, and substance use comes, and some perspective was present in the context of African-Americans.

\section{Social Bond Theory and Substance Use}

The empirical support for Hirschi's (1969) social bond theory's effect on delinquency (Hirschi, 1969, Abbey et al., 2006; Peguero 2012; Peguero et al. 2011; Ryan et al., 2008; Wiatroski et al., 1981) continued into the substance use literature. Empirical research supports the view of attachment to families and schools, commitment to prosocial activities, high levels of conventional involvement, and prosocial beliefs were inhibitors to substance use (Burton et al., 2012; Henry \& Slater, 2007; Hoeve et al., 2012).

Partial examinations of social bond components showed positive results for the theory as well. For instance the attachment bond has been found relevant to various types of substance use among many different samples (Bryant \& Zimmerman, 2002; Ford, 2009; Henry \& Slater, 2007). Ford (2009) used a nationally representative sample of American youth aged 12 or older $(n=55905)$ to examine the impact of social bonds of attachment to school and family on nonprescription drug use. The study's findings indicated that youth with strong bonds to parents and schools are less likely to report 
nonmedical prescription drug use. Ford (2009) described that these strong bonds inhibit substance use due to how youths value their close relationship with parents and believe that substance use will negatively affect these relationships. Furthermore, youth with strong bonds to parents are more likely to have high levels of parental monitoring making substance use less likely. Close monitoring also limits the free time that could result in unstructured socializing with undesirable peers. Strong bonds to schools also applies to the bond of commitment through the investment made toward prosocial activities and goals, which substance use would jeopardize. Finally, results indicated that the bond to school is a stronger negative correlate to drug use than the bond to parents.

Henry and Slater (2007) analyzed data from 4216 junior high youths to examine the effect of levels of attachment to school as a predictor of alcohol related beliefs and behaviors. Results indicated that where students attended schools with an overall trend in greater student attachment they were less likely to use alcohol. Additionally, youth in these schools also have lesser alcoholic intentions, perceive fewer of their peers use alcohol, and hold aspirations inconsistent with alcohol use.

Furthermore, the bond of commitment to various potential sources has also been found to be correlated with drug use in the anticipated direction (Ford, 2005; Hope \& Cook, 2001; Ryan et al., 2008). Ford (2005) studied commitment and attachment to family as a negative predictor of substance use and general delinquency in a national sample of American youth. He found family attachment and commitment was significantly and negatively related to both marijuana use and general delinquency.

Beyond commitment to school and family youth may be committed to religious organizations such as churches. Hope and Cook (2001) examined commitment in a 
religious context as a predictor of substance use among juveniles (12-16) and young adults (17-30). Self-report questionnaires were administered to 7661 participants. Higher levels of religious commitment was generally associated with a lesser likelihood of smoking, being drunk, and doing drugs.

Following in suit of attachment and commitment, several empirical results also support the bond of belief's predictive abilities to substance use (Longshore, Chang, Hsieh, \& Messina, 2004). Longshore, Chang, Hsiesh, and Messina (2004) tested the belief aspect of social bond on male drug offenders. Belief was significantly and negatively related to substance use. Furthermore, the study included measures of selfcontrol as a mediating factor in drug use. The social bond of belief was the only social bond the mediated the relationship between self-control and drug use.

Finally, heavy involvement in prosocial activities was also identified by several researchers as associated with reduced substance use (Fredricks \& Eccles, 2005; Li, Zhang, Liu, Arbit, Schwartz, Bowers, \& Lerner, 2011). Li et al. (2011) studied school engagement and involvement on risky adolescent delinquent behaviors. The study utilized 7 years of longitudinal data collected from youth and their parents from the 4-H study of Positive Youth Development study of U.S. youth. Results indicated that controlling for demographic data high levels of school involvement and engagement was significantly associated with lower risk of involvement in delinquency.

Fredrick and Eccles (2005) tested the relationship school-based extracurricular involvement and youth development. The study utilized an all-white sample of American high school students $(n=498)$ from the Childhood and Beyond (CAB) study. Results indicated the youth who were more involved in school-based extracurricular activities 
had greater academic success, psychological wellbeing, and pro-social behavior. A further study included a gendered analysis that showed gender to be potential moderator to developmental trajectories towards delinquency and differences in the benefits of extracurricular activity (Fredrick \& Eccles, 2006).

Bryant and Zimmerman (2002) found students that liked school and were interested in school were negatively correlated with substance use. The study involved substance use among $10^{\text {th }}$ and $12^{\text {th }}$ grade students, predominantly African-American $(\mathrm{n}=785)$, from urban locations. Results indicated that truancy from school, low achievement and motivation in school was associated with higher rates of substance abuse. Furthermore, adolescents who perceived negative school attitudes in their peers were more like to engage in substance use. Even among high achieving students, low levels of motivation was a risk factor for increased substance use.

Specifically, regarding African-Americans, social bonding had been found a relative correlation to adolescent drug use. Ellickson, Tucker, Klein, and McGuigan (2001) found low social bonding predicted early onset of substance use among AfricanAmerican youth. Abbey et al., (2006) found school commitment and involvement in after school activities were negatively associated with substance use among African-American adolescents.

In summary, empirical research has established the positive connection between the presence of the four social bonds (Hirschi, 1969) and lower rates of delinquency including substance use among various samples including African-Americans (Abbey et al., 2006; Ellickson Tucker, Klein, \& McGuigan, 2001). Analyzing the four bonds separately provided additional support for the theory. Attachment to parents and schools 
(Ford, 2005; Hope \& Cook, 2001; Ryan et al., 2008), commitment to family and educational pursuits, (Ford, 2005; Hope \& Cook, 2001; Ryan et al., 2008), involvement in prosocial activities (Fredricks \& Eccles, 2005; Li, et al., 2011) and acceptance of conventional norms (Longshore et al., 2004), had been associated with controlling drug use among youth. Furthermore, social bond theory (Hirschi, 1969) had been useful in explaining delinquency in the context of sport participation (Sandford, Armour \& Washington, 2006; Crosnoe 2001; Eccles \& Barber, 1999; Juvonen et al., 2012; Larson 1994; McNeal, 1995). An important distinction to note in the current dissertation is the role social bonding has played in power vs non-power sports. The social bonds provided from sport participation as associated with prosocial development are mostly associated with non-power or contact sports (Crosnoe 2001; Eccles \& Barber, 1999; Juvonen et al., 2012; Larson 1994; McNeal, 1995). However, scholars have contended that participation in power sports and assimilation into group norms as associated with power and contact sports have been associated with greater rates of delinquency (Kreager, 2007).

This dissertation's application of social bonds to youth sport participation and substance use was an important line of study as both sport participation holds a prominent position in the lives of American youth and substance use is very common among American youth, including African-Americans (Johnston et al., 2013; NFSHSA, 2011). Furthermore, substance use has been associated with negative life outcomes such as cognitive and physical impairment, unsafe sex, and health consequences (Cooper, 2002; Hingson et al., 2005; Townshend \& Duka 2005; Gogtay et al., 2004; Gruber et al., 2003). Few studies existed in the empirical literature in the context of binge drinking much less 
with all African-American samples and for sport participation. This indicated a gap in our understanding in the social bonding literature.

\section{Social Learning Theory}

In addition to social bonding theory, other theoretical premises could be used to provide a context for sport participation and binge drinking among African-Americans. Specifically, Akers' (1998) version of social learning theory provided information about the importance of peers in learning deviant and criminal behavior. While participating in sports could provide a positive socializing environment, with worn or broken bonds, the possibility existed that peers on sports teams may provide an opportunity to learn behavior that includes binge drinking.

To provide an understanding of Akers's (1998) social learning theory, it was important to understand the four main concepts of the theory. Specifically, these were (1) differential association, (2) definitions, (3) differential reinforcement, and (4) imitation. Differential association involved the social interactions between people in peer groups, for example, families, neighborhoods, classmates, or sports teams. The groups contained the settings in which interactions between individuals in these groups take place and the social learning of behaviors occurs. The most important of these groups, according to Akers (1998) was the intimate personal groups including friends and family, due to their significant role in the individual's life.

The second key component from social learning theory (Akers, 1998), definitions, is were related to an individual's system of beliefs and attitudes that they assigned to certain behaviors. Included in these definitions are orientations, rationalizations and attitudes that describe an act delinquent or non-delinquent (Akers, 1998). Akers (1998) 
described how these definitions were learned through social reinforcement and referred to as "discriminative stimuli" in that some behaviors are likely to be rewarded or punished. The perceived reward or punishment motivates behavior, despite whether participation in such an act was consistent with someone's beliefs (Akers, 1998).

According to Akers (1998) the next component, differential reinforcement, involved the rational cost-benefit calculation of the anticipated or actual rewards or punishments that are consequences of certain behaviors. The probability of engaging in a behavior increased or decreased alongside certain desirable or undesirable rewards and punishments (Akers, 1998). The concept of differential reinforcement's effect on behavior extended from Skinner's (1953) model of operant conditioning involving positive and negative reinforcement and positive and negative punishment. Rewards such as money, status, or excitement as associated with a behavior, according to the theory, are positively correlated with committing such behavior. In terms of negative reinforcement, this correlation remained when behavior was associated with a low frequency and severity of punishment. Punishing behavior could have a deterrence effect through direct (positive punishment) and indirect (negative punishment). Positive punishment involved the undesirable consequences that result from a behavior. Negative punishment was when behavioral consequences involved the loss of a valued reward.

Akers (1998) described the last component, imitation, as the modeling of a behavior witnessed in others. The imitation component was linked to Bandura's (1979) view known as vicarious reinforcement in which people observed modeled behaviors in others and the following consequences of such behavior others experience. For instance, a witness to a criminal act recognized the rewards or lack of punishment and can be 
encouraged to participate in an act through imitation. Akers (1998) described two forms of imitation, the first coming through direct observation (witnessing those in peer groups) and the second was indirect observation (behaviors witnessed in the media). The unique power that imitation brought to the social learning process depends on certain factors. Specifically, characteristics of the model and the behavior being observed along with reinforcement factors all affect the likeliness of the behavior being imitated (Akers, 1998). Akers (1998) contended that direct observations are those most imitated, but also believed that indirect media figures could serve as imitation models.

Akers's (1998) social learning theory was embedded in a larger social process embedded within three areas (1) an individual's learning history (both learning from and influencing others), (2) immediate situations where opportunity for a crime occurs, and (3) in the larger social context (i.e., meso- and macro levels). In order for social learning to occur, reciprocal and feedback effects are essential. Reinforcement relied on a response-stimulus-response reciprocation similar to logic from skinner (1953) and Akers (1998) use of operant conditioning. To clarify, a behavior results in consequences that create a certain likelihood of replication of such behavior. This suggested that the theory was more complex than just the merger of the four components.

The typical temporal sequence in the process by which persons come to the point of violating the law, or engaging in other deviant acts, is hypothesized to be one in which the balance of learned definitions, imitation of criminal or deviant models, and anticipated balance of reinforcement produces the initial delinquent or deviant act. The facilitative effects of these variables continue in the repetition of acts, although imitation becomes less important than it was in the first commission of the act. After onset or initiation, the actual social and non-social reinforcers and punishers affect whether or not the acts will be repeated and at what level of frequency. Both the behavior and definitions, favorable and unfavorable, are affected by the consequences of the initial acts. Whether a deviant act will be repeated in a situation that presents, or is perceived to present, the opportunity depends on the learning history of the individual and the set of 
definitions, discriminative stimuli and reinforcement contingencies in that situation (p. 41).

This did not provide a definitive picture of the only way social learning concepts may occur. Rather, certain concepts of the social learning process may occur in various sequential orders. For example, definitions were thought to form before carrying out a crime. However, Akers (1998) hypothesized that definitions may form at any time during the social learning process. For example, definitions forming before an act was carried out was certainly possible, but definitions also may form in hindsight to an act to justify or excuse a behavior. Even at the retrospective point in the social learning process, the inhindsight nature of the justification or excuse may remain a definition applied towards future behavior applying to the response-stimulus-response reciprocation associated to reinforcement.

\section{Empirical Support for Social Learning Theory}

Much empirical research supports the aspects of social learning perspective in predicting delinquency including binge drinking (Akers \& Jensen, 2006; Bahr et al., 2005 Pratt, Cullen, Sellers, Winfree, Madensen and Diagle, 2009; Steele, Peralta, \& Elman, 2011; Ward \& Gryczynski, 2009; Wright \& Cullen, 2000). Wright and Cullen (2000) studied the workplace misconduct of juveniles. With a sample of high school seniors $(n=436)$, they sought to explore the determinants of juvenile occupational delinquency. Due to the interest in studying how the quality of the work environment affects delinquency they included measures of the nature of the social relationships at work. Contact with delinquent peers is a common measure of differential association (Akers, 1998). 
Included in the study respondents were asked to report how often coworkers and supervisors engaged in delinquency. Notably, the measure of associations with delinquent coworkers was a significant and positive predictor of occupational delinquency. This finding remained strong even after controlling for delinquent propensity, past delinquency, and self-control. Therefore, the coworker-delinquency relationship appears more than spurious and not just due to individual differences brought to the workplace. Furthermore, associating with delinquent peers at the workplace may increase delinquency in other areas of life.

Akers and Jensen (2006) reviewed the empirical evidence on the validity of social learning theory (Akers, 1998) and theory's ability to explain criminality. They found that previous work established the validity of the theory and proposed, "the theory has been tested in relation to a wider range of forms of deviance, in a wider range of settings and samples and by more different people. The theory has survived more "crucial tests" against other theories, and is the most strongly and consistently supported by empirical data than any other social psychological explanation of crime and deviance (Akers \& Jensen, 2006)."

Pratt, Cullen, Sellers, Winfree, Madensen and Diagle (2009) subject the wide body of social learning literature to a meta-analysis. Inclusion of studies was based on analysis of social learning variables that were published in the leading criminal justice/criminology journals from 1974 to 2003 ( $\mathrm{n}=133$ ). Results indicated that the relationship between differential association and definitions and delinquency are quite strong but results regarding differential reinforcement and imitation were more modest. 
Effect sizes differed significantly for differential association, definitions, and differential reinforcement according to variations in model specification and research design.

Akers' (1998) social learning theory has been found a predictor of delinquency among African-American exclusive populations as well. Simons and Burt (2011) establish connections between crime and social factors including deviant peer association in a sample of 700 African-American teens.

\section{Social learning Theory and Binge Drinking}

This empirical vitality of social learning theory (Akers, 1998) also includes studies of binge drinking by youth (Bahr et al., 2005; Hahm, Kolaczyk, Jang, Swenson, \& Bhindarwala, 2012; Hahm, Guterman, \& Lahiff, 2004; Kreager \& Haynie, 2011).

Hahm, Guterman, and Lahiff (2004) studied the link between acculturation and subsequent binge drinking in a sample of 90,000 Asian-American $7^{\text {th }}$ through $12^{\text {th }}$ grade students as related to the mediating effect of friends' alcohol use. Findings indicated that acculturation is not directly associated to binge drinking, but social interaction with alcohol using peers was a pathway to which acculturated Asian-Americans are at risk for binge drinking behaviors. The findings were related to Akers and Lee's (1996) assertion of adopting U.S. cultural values leads to an increased reliance on peers as a source of behavior codes and values.

Using social learning theory as a framework, Kreager and Haynie (2011) studied dating and peer networks to understand the diffusion of binge drinking behaviors in school based friendship networks. Data was taken from the 1994-1995 National Longitudinal Study of Adolescent Health involving 90,000 students in grades 7 through 12. They argued that romantic relationship change social structures of peer networks and 
create friendship ties of friends-of-partners who may influence adolescent drinking. Findings were consistent with the social learning and differential association perspectives in that friends and romantic partners were significant others with the potential to shape an adolescents behavior towards future binge drinking. Furthermore, drinking behaviors of friends-of-partners had a large association with adolescent drinking.

Hahm, Kolaczyk, Jang, Swenson, and Bhindarwala (2012) investigated the association between the characteristics of a youth's social network and binge drinking behaviors using the National Longitudinal Study of Adolescent Health ( $\mathrm{n}=7966)$. Group integration and socialization with substance using peers had an immediate impact on binge drinking during adolescents. Furthermore, the patterns of binge drinking gradually increased from adolescence to young adulthood in association with social network characteristics. Specific results indicated that those with alcohol using peers were nearly ten times as likely to participate in early onset binge drinking behaviors. Hahm et al. (2014) contended that this may be explained by social learning theory in that youth were more likely to respond when faced with an offers and encouragement to drink.

Bahr, Hoffman, and Yang (2005) used a probability sample of 42307 to 12 graders and estimated the effect of peer and family variables as related to youth binge drinking. Several measures related to social learning theory (Akers, 1998), including parental attitudes towards substance use, peer and sibling drug use had significant direct effects on youth binge drinking. Bahr et al., (2005) interpreted these findings as consistent with the social learning premise.

An important issue with these studies is that none have addressed the specific problem of African-Americans and binge drinking. This gap in the literature is relevant to 
the advancement of theory and practice related to African-Americans and binge drinking, which according to the literature regarding rates of African-American participation in and the negative health consequences of binge drinking is a vital line of study. Previous studies have shown that binge drinking is common among African-American youth ( Johnston et al., 2013) and the consequences of binge drinking include physical injuries, cognitive impairments, unsafe sexual activity, and liver and kidney damage (Cooper, 2002; Hingson et al., 2005; Rehm, et al., 2010; Townshend \& Duka 2005; Yamagata, et al., 2007).

\section{Social Learning Theory and Sports Participation}

Empirical research has indicated that social learning can play a role in deviance committed by athletes. Hughes and Coakley (1991) studied deviance by athletes through the lens of social learning theory as opposed to social alienation or rejected cultural values. They contend that deviance is a direct result of normative definitions learned in sports, or in their own words - "positive deviance." Hughes and Coakley (1991) contended that values associated with sports such as striving for excellence and distinction, sacrifices for the greater good of the team, playing despite painful experiences, and overcoming limits can be associated with general success in life and non-deviant behavior. However, these values can also cause athletes to do harmful things to themselves and perhaps others while motivated by a sense of duty and honor.

They point to the example of performance enhancing drug use by athletes. Although performance enhancing drugs are considered deviant by mainstream society, within the context of sport participation they are considered acceptable while being modeled and reinforced. Similarly, aggressive and violent acts could be recognized as a 
means of success on the field. Athletes became accustomed to violence and intimidation and apply them to other goals and problems off the field. Peer relationships played a crucial role in this learning process. Kreager, (2007) found that individuals whose friends played football were more likely to fight than those with non-football playing friends, supporting the peer contexts premise as a valid mediator. Essentially, findings were consistent with the social learning premise. Violent tendencies can even be perpetuated by school authority figures and coached into players. Football coaches, sources of behaviors to be modeled, have often used verbal abuse towards their players and condoned the violent acts of players, with players experiencing increased levels of anger (Bennett, 1990; Beyer \& Hannah, 2000; Lombardo, 1986). Coleman (1961) contended that in the adolescent years youth are highly status-conscious among peer groups. As previously mentioned, sports participation and substance use are pathways to gaining higher status among peers (Eder \& Kinney, 1995; Peralta, 2007).

The social learning (Akers, 1998) theoretical premises are highly relevant to the sport environment. Theoretically, the same concept of sports that emphasize aggression and contact, being linked to greater violence among participants as encouraged by the team environment can be applied to substance use among athletes. However, there is limited research on the predictive abilities of participation in specific sports as related to substance use. Partington et al. (2013) studied the susceptibility of peer influences and peer socialization factors in a team environment with a sample of those participating in university sports in the UK $(n=770)$. In comparison of those participating in individual sports, team sport members were more likely to drink significant amounts of alcohol on more frequent occasions and experience greater risk for alcohol related harm. 
Other research has supported this concept of team sport participation being linked to greater alcohol consumption vs individual sport participation (O'brien \& Lyons, 2000; Peretti-Watel et al., 2003). O'brien and Lyons (2000) found that 88 percent of college athletes participate in alcohol consumption and that the kind of sport played was associated with level of intake. In terms of drinking behaviors, players of rugby, cricket, soccer, and football had the highest percentage of alcohol consumption while those involved in horseracing, cycling, and tennis consumed the least amounts of alcohol. Noticeably, the sports associated with team play had greater levels of drinking.

However, Ford (2007) found that alcohol consumption among male soccer team players was low, yet consumption among female soccer players was high. Ford (2007) suggested that the social networks within sports could be unique and account for the different findings. Furthermore, there may be differences in the cultural attitudes towards substance use that are encouraged by specific teams. Parington et al. (2003) also studied alcohol intake as studied according to the competitive level of the sport. They found no significant differences in relation to competiveness level expect for the frequency of heavy episodic drinking. This contrast to other studies (Green, Uryasz, Petr, Bray2001; O'brien, Blackie, \& Hunter, 2005) which found that more elite sport participants were more likely to engage in alcohol use.

In terms of African-Americans specifically, sports participation can create opportunities for delinquent peer association. Taylor and Turek (2010) found that in a sample of African-American girls, sport participants reported higher levels of peer use of all substances in rural areas, and higher levels of peer alcohol use in urban settings. 
In summary, social learning theory (Akers, 1998) has been a prominent explanation of delinquency that has been subjected to much empirical testing. The four social learning components (differential association, differential, definitions, imitation) have been related to delinquency including substance use in the anticipated direction for many different samples (Bahr et al., 2005; Hahm et al., 2012; Hahm et al., 2004; Kreager \& Haynie, 2011).

Social learning theory (Aker, 1998) has also been found relevant to the social environments related to sports participation and have helped to explain the delinquency and non-delinquency of athletes including substance use (Endresen \& Olweus, 2005; Hughes \& Coakley, 1991; Kreager, 2007). Importantly, the social learning theory, sport participation, and alcohol use literatures indicated that different sports may have more influence on the behavior. One important note is the difference between deviant peer association and exposure to aggressive role models as associated more with power sport participation than non-power sport participation (Endresen \& Olweus, 2005; Kreager, 2007). Scholars have found that this greater exposure to deviant peers and role models have led to greater levels of delinquency as related to the social learning theoretical premise (Endresen \& Olweus, 2005; Kreager, 2007).

This is vital, as participation in various sports is very common among youth in the United States (NFSHSA, 2011). Two issues were relevant in this literature. First, no studies used an all African-American sample; thus, no research indicated the relevance of sport participation and binge drinking among African-Americans. Second, no studies in this literature provided an understanding of the different types of sports that would result in African-American binge drinking. 


\section{Current Dissertation}

The current dissertation was designed to fill the gap in the literature involving the ability for specific sports to predict the binge drinking behaviors of their participants. The potential exists for variation in binge drinking among athletes according to unique sport team affiliation in an all African-American sample. The literature indicated that sport participation might foster an environment that either condones or disapproves of substance use and allows the social learning process to take place. This resulted in the following hypotheses:

Hypothesis 1: The type of sport that an individual participates would provide a difference in binge drinking among African-Americans. Hypothesis 2: Consistent with the literature (Endresen \& Olweus, 2005; Kreager, 2007, McCauley et al., 2014) power sport participation would result in African-American youth binge drinking that could be contextualized using social bonding and social learning theories. Considering social bond and social learning theories, it is possible that certain sports like football and wrestling as well as team sports over individual sports will be stronger predictors of binge drinking. Social learning (Akers, 1998) and social bond (Hirschi, 1969) theory would contend that peers would have a greater impact on behavior in a team sport as opposed to individual sports. Hypothesis 3: Gender will play a role in moderating the effect of sport participation on delinquency. Overall, the current dissertation provided information that helps to recognize patterns of binge drinking among African-American athletes. If supported by research, such a contention would aid administrators in targeting populations for binge drinking interventions. 


\section{CHAPTER III}

\section{MATERIALS AND METHODS}

Chapter one discussed the problem of substance use among adolescents and the theoretical framework regarding specific sport participation's potential effect on substance use. Chapter two detailed the theoretical framework of the study including social bond, social learning, and the empirically supporting literature in regards to sport participation and delinquency. Chapter three will describe the methodology of the study. The source and background of the data, the coding of variables and the analysis strategy will be presented.

\section{Procedures and Sampling}

The data necessary for this study needed to include a large enough number of African-Americans, binge drinking, sport participation and demographic measures. The Monitoring the future data set provided most of this information. The Monitoring the Future: A Continuing Study of American Youth (MTF) data came from a larger study. Specifically, this study was an annual cross-sectional survey of secondary school students in the United States (Johnston et al., 2013). Data were collected from nationally representative samples of eighth and tenth grade and twelfth grade students, allowing for a large sample of adolescents to examine the relationship between sport participation and binge drinking (Johnston et al., 2013). The Monitoring the Future survey was conducted by the University of Michigan's Institute for Social Research and funded through various grants from the National Institute on Drug Abuse (Johnston et al., 2013). 
The sampling procedure involved administering self-reported questionnaires to a nationally representative sample of public and private school students in the United States. This administration proceeded in a series of steps. The first step in the sampling procedure focused on particular geographic areas from which respondents would be selected. These geographic units served as the primary sampling units (PSUs) and were developed by the Sampling Section of the Survey Research Center (SRC) to be used for their nationwide interview studies.

The second step involved choosing and gaining cooperation from schools to be selected from the PSUs. In major metropolitan areas, multiple schools were usually included, but in other geographic areas usually only one school was selected. The objective behind the geographical selection of schools was to make each school's probability of being selected proportionate to the number of eighth and tenth graders or senior class in that particular school.

When a selected school refused participation, a replacement within the same PSU was selected while attempting to maintain similarities between original and replacement schools. This replacement school selection nearly removes all problems of bias in region, urbanity, and other complications from a school's refusal to participate (Johnston et al., 2013). However, another potential bias is that schools with a known drug problem may refuse to participate or if any other factor was common in school refusals. However, the investigators believe that schools' reasons for not participating in the sample did not seriously bias the survey due to the variance in and happenstance nature of the reasons for not participating (Johnston et al., 2013). 
Finally, the third step involved selecting students within the school as the sample to complete the questionnaire. For each school selected, a maximum of 350 students participated in the survey completion. These students were selected through random sampling or an alternative and unbiased random procedure. Questionnaires were completed by 85 to 91 percent of all eighth and tenth graders sampled and 75 to 80 percent of twelfth graders. Given this high response rate of the questionnaires, a large portion of the sample admitting drug use, and the consistency of findings across years the potential for non-response bias and self-report biases is reduced (Johnston et al., 2013).

The most common reason for students to fail to complete a questionnaire was that they were absent from class on the day of survey administration with follow-up scheduling for survey completion not possible. Research has shown that students with high rates of absenteeism also having higher rates of drug use (Henry, Knight, \& Thornberry, 2012), some bias had presented itself by the failure to survey absent students. A possible correction to the bias includes the use of special weighting, however, this was not executed because the bias in estimates was determined to be minor and undesirable complications would arise from the weighting procedure. Other students were not surveyed due to their own refusal to participate or a parent's lack of consent. This was not problematic as SRC representatives estimate this population to be about 2 percent of the eligible eighth and tenth and twelfth grade sample. Sample weights were assigned to survey respondents to account for the different sample sizes and selection probabilities of all selected schools.

The Monitoring the Future dataset for the current dissertation was obtained through the Interuniversity Consortium for Political and Social Research (Johnston et 
al., 2013). The Monitoring the Future eighth and tenth grade and twelfth grade surveys administered one of four forms to nationally representative samples of eighth and tenth grade students and twelfth grade students in the United States, with the forms being identical.

The current dissertation seeks to explore the relationship between sport participation and substance use among a sample of eighth and tenth grade $(\mathrm{n}=2197)$ and twelfth grade ( $\mathrm{n}=721)$ African-American students in the United States. The issue with examining African-Americans is that on year of the MTF will not contain enough African-Americans to provide a solid sample. Multiple years of the MTF were used to provide enough African-American responses. Specifically, this study used the 2012 (323 eighth graders; 351 tenth graders; 233 twelfth graders), 2013(407 eighth graders; 297 tenth graders; 239 twelfth graders), and 2014 (489 eighth graders; 330 tenth graders; 249 twelfth graders) years of data collection. Using these years produced a combined total of 2918 African-American responses.

\section{Measures}

The dependent variable of the studies was binge drinking. Key independent variables involve participation in various sports (e.g., football, basketball, baseball, tennis, track, wrestling). Also included are independent variables related to school discipline and performance, family and home background, and individual demographics. Specifically, this involves school suspensions, single-parent household status, age, gender, mother's employment, geographic region, urbanacity, years of survey, and grades. More detailed descriptions of the variables used in the study will be given in the proceeding sections. 


\section{Dependent Variable}

The dependent measure of the study is related to a respondent's participation in recreational substance use, specifically, binge drinking. Binge drinking comes with significant individual health and public safety consequences including physical injuries, cognitive impairments, unsafe sexual activity, and liver and kidney damage (Cooper, 2002; Hingson et al., 2005; Townshend \& Duka 2005; Gogtay et al., 2004; Gruber et al., 2003) making their study as related to youth practically and theoretically valuable.

To measure binge drinking the specific survey item "Think back over the LAST TWO WEEKS. How many times have you had five or more drinks in a row? (A "drink" is a glass of wine, a bottle of beer, a wine cooler, a shot glass of liquor, a mixed drink, etc.)" was responded to by study participants. This definition of binge drinking is consistent with that from Wechsler et al., (1995). Responses were recoded dichotomously to report those that had no occurrences of binge drinking in the past two weeks (0) and those that had at least 1 occurrence of binge drinking in the past two weeks (1).

The dependent variable was a single item indicator. This sort of item is consistent with the extent literature on binge drinking. For instance, several scholars have used this single item indicator of binge drinking to study the prevalence, predictors and consequences of binge drinking (Hahm et al., 2004; Kreager \& Haynie,, 2011; Hahm et al., 2012; Bahr et al., 2005; Johnston et al., 2013; Cooper, 2002; Hingson et al., 2005)

\section{Independent Variables}

The independent variables included in the data analysis are related to a youth's sport participation, school discipline and performance, family and home background, and individual demographics. The independent variables of the current dissertation are 
grounded in the power sport hypothesis (Endresen \& Olweus, 2005; Kreager, 2007) along with the social bond (Hirschi, 1969) and social learning premises (Akers 1998).

\section{Sports Participation}

Furthermore, students' social bonds and sense of belonging to schools and deviant peer association have been found to be influenced both positively and negatively by sports participation (Eccles \& Barber, 1999; Juvonen et al., 2012; Mahoney \& Cairns, 1997; Miller et al., 1998). Hirschi's (1969) bond of attachment refers to an individual's consideration towards the opinions of others to whom they have greater attachment. In other words, attachment involves the level of affection and respect an individual has for significant others including parents, teachers, friends, etc. Individuals have been found to be less likely to participate in delinquency when highly attached to others (Hirschi, 1969). According to Hirschi (1969), those who lack attachment are more likely to commit delinquency as they feel no guilt in behaving contrary to norms of conventional society.

Beyond attachment, the bond of commitment is a factor in the social bond premise related to the investment or stake in conformity that an individual has put forth to a nondeviant pursuit. Those who invested a great deal in succeeding at their sports may not want to jeopardize their hard work by being caught with possession or drugs. Furthermore, the negative health effects of recreational drugs have been found to diminish some types of athletic performance (Penderson et al., 1992). However, research has also found that those who have made a greater investment and are more heavily involved in their sport are more likely to participate in binge drinking (Hildebrand et. al., 2001). 
The bond of involvement is present in sport participation in that athletics often require large dedications of time leaving less of an opportunity for time spent in deviant behaviors (McNeal 1995). Hirschi (1969) contended that "of the elements of the bond to conventional society, involvement in conventional activities is most obviously relevant to delinquent behavior." Hirschi (1969) assumed that participation in wholesome activities, such as sports, are directly incompatible with delinquency. However, involvement is frequently considered the least important of the four social bonds as research has found the involvement element to be a weak or insignificant correlate in controlling delinquency (Jenkins, 1997; Junger \& Marshall, 1997; Leonard \& Decker, 1994).

Beyond social bond theory (Hirschi, 1969) youth sports participation is also related to social learning theory (Akers, 1998). Theoretically, certain sports teams can foster an environment that either condones or disapproves of substance use and allows the social learning process to take place. Some have found that sports participation, particularly power sports are a pathway to deviant peer association (Endresen \& Olweus, 2005; Kreager, 2007). According to Akers' (1998) social learning theory begins with differential association to deviant peers from who deviant behaviors are learned along with definitions, differential reinforcement, and imitation. Akers (1998) considered intimate personal groups, such as sport teammates, to be most significant to the social learning process. Hughes and Coakley (1991) have shown how sport participation can effect an individual's definitions regarding performance enhancing drugs, considered deviant by mainstream society, are encouraged among athlete settings, allowing for modeling and reinforcement among athletes. Furthermore, those involved with team sports over individual sports have been found more likely to participate in delinquency, 
due to the susceptibility of peer influences and peer socialization factors among team members (O’brien \& Lyons, 2000; Parington et al., 2013).

The primary question used to gauge sport participation included: "In which competitive sports (if any) did you participate during the last 12 months? Include school, community, and other organized sports (mark all that apply).” The competitive sports from which respondents could select and included in this analysis were as follows: baseball, basketball, cheerleading, football, tennis, track, and wrestling). Participation in each sport was measured dichotomously $(0=$ no, $1=y e s)$. Items were used individually in data analysis. This measure of sports participation was chosen because the measure allows for the power sport hypothesis (Endresen \& Olweus, 2005; Kreager, 2007) to be examined in our study's theoretical framework. Essentially, these variables are included to test whether participation in aggressive or antisocial sports is related to higher rates of delinquency, in our case substance use. As indicated in the previous sections there is evidence to suggest that participation in "power sports" is significantly related to delinquency (Endresen \& Olweus, 2005; Kreager, 2007). Furthermore, these sports fit our theoretical perspectives, as type of sport played has been associated with deviant peer association, positive deviance, and school bonds (Hughes \& Coakley, 1991; Kreager, 2007)

\section{Other Independent Variables}

To gauge disciplinary actions taken against them respondents were asked if they were ever suspended from school. Specifically, "Have you ever been suspended or expelled from school?" was asked with answer choices measured as 0 equaling no and 1 equaling yes. This variable holds theoretical significance to the social bond (Hirschi, 
1969) and differential association (Akers, 1998) premises. Research shows that students who have been suspended from school have weaker bonds towards their school (Eith, 2010), and the bond of involvement is clearly related to time spent in school. Further, school suspensions can be a pathway to deviant peer association, a lack of supervision, and a lost opportunity to spend time with conforming classmates (Arum \& Beattie, 1999). Social learning theory (Akers, 1998) defines deviant peer association, or differential association as the first of four components in the social learning process. The concept of differential association features the social interactions between peer groups from whom deviant behaviors are learned.

A subject's gender was captured in survey responses $(0=$ female and $1=$ male). To capture a respondent's ecological surroundings, the survey item "Where are you living now?" was included. Potential responses were coded as such: 1 (On a farm), 2 (In the country, not on a farm), or 3 (In a city or town). Responses were recoded dichotomously so that 1 equaled residing in an urban area and 0 residing anywhere else.

The survey also inquired into the level of education achieved by a respondent's mother and their mother's working status. Specifically, respondents were asked "What is the highest level of schooling your mother completed?" Responses were coded as $1=$ "Completed grade school or less" $2=$ "Some high school" $3=$ "Completed high school" 4="Some college" $5=$ college graduate" and 6="graduate or professional school." To capture whether a youth had a working mother respondents were asked "Does your mother have a paid job?" Responses were coded 0 no and 1 yes. The social bond and deviant peer association premises are related to parental working status in that youth with 
less parental supervision have been found to form deviant peer associations and have lower levels of supervision from and attachment to their parents (Aizer, 2004).

Whether a respondent resided with a single parent was measured through the question "Which of the following people resided in the same household with you?" Responses were coded so that 1 equaled a single parent household and 0 did not. Previous research has shown that residing in single parent households can effect youth behavioral problems including alcohol use in many ways (Griffin, Bitvin, Scheier, Diaz, \& Miller, 2000; Lucero, Barret, \& Jensen, 2015; Osbourne, 2007; Vanaache, Sodermans, Matthijs \& Spicewood, 2013). Theoretically, youth residing with only one parent have less of an opportunity to develop strong parental attachment and are more likely to be exposed to deviant peers (Griffin et al., 2000). Respondents also reported which region of the country they resided. Responses were coded as 1 (south), 0 (Northeast), 0 (North Central), and 0 (West) to asses any effect of regional differences.

Also included was a dichotomous ( $0=$ no, $1=$ yes $)$ measure of whether the respondent belonged to the 2012, 2013, and 2014 cohort of data collection was also included. To measure the academic performance of students the flowing was included "Which one of the following best describes your average grade in this school year?" Coding of potential responses were as follows: 9="A (93-100)" 8="A- (90-92) 7="B+ (87-89)" 6="B (83-86)" 5="B- (80-82)" 4="C+ (77-79)" 3="C (73-76)" 2="C- (70-72)" $1=" \mathrm{D}(69$ or below)."

\section{Analysis Plan}

Analysis of the data will proceed in two steps. First descriptive statistics for the samples will be presented to show the distribution of the data. The descriptive statistics 
presented include mean, standard deviation, and minimum and maximum values to gauge the distribution of the data. The mean, defined as the arithmetic average of the sample's responses to each survey item, provides the average of the survey responses from the sample. The standard deviation, defined as a measure of dispersion, or how far spread all the values are from the mean shows the variation or heterogeneity among survey responses. The minimum and maximum values show the potential for the lowest and highest survey responses that received at least one response. Following descriptive statistics logistic regression will be used to gauge the explanatory power of the independent variables on participation in and binge drinking in the past 2 weeks. Logistic regression involves regression of multiple independent variables on the occurrence of a dichotomously measured dependent variable. Data analysis was performed with the STATA 14 data analysis and statistical software package.

Given the complex survey data collected across schools and that the observations may be correlated within schools, a cluster analysis with robust standard errors was included. This procedure estimates standard errors using the Huber-White sandwich estimators (Huber, 1967; White, 1982). The robust standard errors take into account that the observations within schools are non-independent and issues concerning heterogeneity and normality.

Robust standard errors are vital as survey research often ignores factors such as clustering, stratification, or weighting (Lumley, 2004). This results in biased estimates of standard errors and a higher likelihood of Type 1 errors. Clustering can underestimate true population variance, resulting in standard errors larger than those obtained from 
simple random sample. The use of robust standard errors correctly reflect sampling variability due to complex survey design.

The sandwich estimator for standard errors are useful when model based estimators are complex and require robust alterative, common with cluster samples. The idea is that clusters are independent, but subjects within a cluster are dependent. The sandwich estimator is formed by replacing the estimate of the central covariance term by an empirical estimator based on the (block diagonal structure) cross product matrix. 


\section{CHAPTER IV}

\section{RESULTS}

Chapter 1 described the problem of juvenile drug use, as well as examined sport participation's potential effect on the decision to participate in substance use. Chapter 2 further detailed the study's theoretical perspective as well as the existing literature within the domain of sport participation and delinquency. Chapter 3 laid out the data, variable coding, statistical techniques that were utilized in this dissertation. Chapter 4 will describe the results of statistical analysis between independent and dependent variables. As described in the previous chapter the analysis plan will include a three step process. This includes descriptive statistics, bivariate correlations, and binary logistic regression.

\section{Results}

\section{Step 1}

Step 1 of the analysis plan is the presentation of descriptive statistics. These include the mean, standard deviation, and minimum and maximum values. These statistics are necessary to describe the representation, spread, and normality or each variable. Considering that the variables mother's working status, single parent household, school suspensions, urban residence, geographic region, cohort or data collection, and the various types of sport participation are dichotomous, their standard deviations is not presented.

Descriptive statistics for the eight and tenth grade sample of African-Americans for the current dissertation are included in table 1. In terms of our dependent variables, 
we see that 5 percent of males and 6 percent of females in the sample report binge drinking in the past 30 days. Regarding sports participation basketball is the most popular sport with nearly 43 percent of the sample participating. Following basketball, there is also a large amount of participation in football ( 27 percent). This is significant to the current study's utilization of the power sport hypothesis (Endresen \& Olweus, 2005; Kreager, 2007). Empirical research has found that participation in certain sports, particularly power sports and contact sports to be related to an increase in delinquent behaviors including substance use compared to other noncontact sports (Endresen \& Olweus, 2005; Kreager, 2007). Similarly, high levels of respondents participated in track (21 percent). There are comparable levels of participation in baseball (11 percent) and cheerleading (11 percent). The sports with the least participation include tennis and wrestling both containing 3 percent of the sample. 
Table 1. Descriptive Statistics Eighth and Tenth Grade Sample (n=2197)

\begin{tabular}{|c|c|c|c|c|c|c|c|c|c|}
\hline \multirow[t]{2}{*}{ Variable } & \multicolumn{3}{|c|}{ Totals } & \multicolumn{3}{|c|}{ Males } & \multicolumn{3}{|c|}{ Females } \\
\hline & mean & St. dev & $\operatorname{Min} / \max$ & mean & St. dev & $\operatorname{Min} / \max$ & mean & St. dev & $\operatorname{Min} / \max$ \\
\hline Binge Drinking & 0.06 & -- & $0-1$ & 0.05 & -- & $0-1$ & 0.06 & -- & $0-1$ \\
\hline GPA & 5.90 & 2.25 & $1-9$ & 5.62 & 1.84 & $1-9$ & 6.19 & 1.84 & $1-9$ \\
\hline Mother's Education & 4.23 & 1.55 & $1-6$ & 4.25 & 1.30 & $1-6$ & 4.21 & 1.27 & $1-6$ \\
\hline Working Mother & 0.83 & -- & $0-1$ & 0.82 & -- & $0-1$ & 0.83 & -- & $0-1$ \\
\hline Single Parent & 0.48 & -- & $0-1$ & 0.46 & -- & $0-1$ & 0.50 & -- & $0-1$ \\
\hline Urbanacity & 0.93 & -- & $0-1$ & 0.92 & -- & $0-1$ & 0.93 & -- & $0-1$ \\
\hline Suspended & 0.44 & -- & $0-1$ & 0.53 & -- & $0-1$ & 0.35 & -- & $0-1$ \\
\hline Geography & 0.57 & -- & $0-1$ & 0.53 & -- & $0-1$ & 0.60 & -- & $0-1$ \\
\hline Cohort 2013 & 0.30 & -- & $0-1$ & 0.12 & -- & $0-1$ & 0.30 & -- & $0-1$ \\
\hline Baseball & 0.11 & -- & $0-1$ & 0.13 & -- & $0-1$ & 0.09 & -- & $0-1$ \\
\hline Basketball & 0.43 & -- & $0-1$ & 0.58 & -- & $0-1$ & 0.27 & -- & $0-1$ \\
\hline Cheerleading & 0.11 & -- & $0-1$ & 0.01 & -- & $0-1$ & 0.21 & -- & $0-1$ \\
\hline Football & 0.28 & -- & $0-1$ & 0.52 & -- & $0-1$ & 0.04 & -- & $0-1$ \\
\hline Tennis & 0.03 & -- & $0-1$ & 0.03 & -- & $0-1$ & 0.04 & -- & $0-1$ \\
\hline Track & 0.21 & -- & $0-1$ & 0.21 & -- & $0-1$ & 0.21 & -- & $0-1$ \\
\hline Wrestling & 0.03 & -- & $0-1$ & 0.06 & -- & $0-1$ & 0.01 & -- & $0-1$ \\
\hline
\end{tabular}


Sports participation has been found to be a significant factor in predicting delinquency and substance use. Some research finds that sport participation is significantly related to stronger school attachment, increased academic achievement, and fewer cases of aberrant behavior (Sanford, Armour, \& Warmington, 2006; Skolnick, 1993). However, some research leads us to believe that sport participation, especially power sport participation (e.g., football, wrestling), is a significant predictor of higher rates of delinquency (Endersen \& Olweus, 2005; Kreager, 2007; McCauley et al., 2014). Theoretically, these results can be examined through the social bond (Hirschi, 1969) premise and deviant peer association (Akers, 1998).

For the demographic variables of our African-American sample, we can see that nearly half the sample lived with a single parent (48 percent). A large number of the sample have a working mother ( 81 percent). This is a significant finding in terms of viewing our results through the lens of social bond theory (Hirschi, 1969). According to Hirschi (1969), the most important source of attachment for youth regarding the prevention of delinquency is attachment to their parents. Hypothetically, youth coming from single parent households have less of an opportunity to build strong bonds with parents. This is exacerbated when single parents are employed due to the lack of time and energy to devote to building strong bonds with their children. Empirical results have supported the view that single parents and parents who work have a weaker bond with their children (Aizer, 1995). Furthermore, the amount of time spent with family has been found to reduce and prevent connections to deviant peers (Warr, 1993).

The sample is well balanced in terms of gender, with 49 percent of the sample being male. Thirty percent of the sample belonged to the 2013 cohort of the data 
collection. On average, the mother's of the research subjects have completed high school as their highest level of education. Ninety-two percent of the sample lived in an urban area and nearly half (44 percent) have been suspended from school. Research has shown that students who are suspended from school are more likely to form associations with deviant peers (Eith, 2010). Fifty-seven percent of the sample lived in the southern region of the United States.

As for gender-specific examination of African-American eighth and tenth graders the table shows that among the demographic variables males and females are highly comparable. Rates of binge drinking indicate that 5 percent of males and 6 percent of females participated in the past two weeks. On average females (6.19) have a slightly higher GPA than males (5.62). For both samples, the average education of their mothers is a some college and approximately 83 percent of both samples have a working mother. Approximately 50 percent of both samples indicated they resided in a single parent household and approximately 93 percent of both samples resided in an urban area. In terms of geographic location 53.9 percent of males resided in the southern United States, while 60 percent of females resided in the south. In terms of sport participation males are most represented in basketball (58 percent), football (51 percent), track (.217), baseball (.128), wrestling (.062), tennis (.031), and cheerleading (.009). Conversely, females are most represented in basketball (.279), cheerleading (.212), track (.212), baseball (.093), tennis (.048), football (.041), and wrestling (.006).

Descriptive statistics for the twelfth grade sample of African-Americans are presented in table 2 . In terms of the dependent variable, binge drinking, there appears to be higher levels of participation among the twelfth grade sample (11 percent). Similar 
results are seen in the demographic factors. Grade point averages are slightly higher than the eighth and tenth grade sample at 6.1 , or mostly Bs. The average education of a respondent's mother is similar to the eighth and tenth grade sample at 4.06 , or some college. Ninety five percent of the twelfth grade sample have a working mother, an increase of 12 percent from the eighth and tenth grade sample. Slightly more the half of the sample have a working mother (57 percent). Thirty eight percent of the sample resided in an urban location. This is significantly less than the eighth and tenth grade sample. Approximately two-thirds of the sample (67 percent) resided in the southern region of the United States. Comparably to the eight and tenth graders approximately one-third of the sample ( 33 percent) belonged to the 2013 year of data collection. In terms of sport participation, basketball saw fewer participants in the twelfth grade sample (32.9 percent). Following basketball, the most popular sports included football, track, wrestling, cheerleading and tennis.

In the gender specific columns of our African-American sample, males engaged in binge drinking (13 percent) more than females ( 9 percent). Females have slightly higher GPAs (6.38) than males (5.79). Males have mothers with slightly higher education (4.25) than females (4.07). Approximately, 83 percent of both samples have working mothers and approximately 50 percent of both samples have single mothers. Approximately 93 percent of both samples resided in urban areas. Slightly more of the female sample (67 percent) resided in the southern region of the United States than the males (60 percent). Males are more represented in baseball (males $=0.095$, females $=0.091)$, basketball (males $=0.492$, females $=0.222$, football (males $=0.521$, females $=0.041)$, track (males $=0.217$, Females $=0.212)$, and wrestling $($ males $=0.062$, 
females $=0.006$ ). Females are more represented in cheerleading (males $=0.009$, females $=0.212$ ) and tennis (males $=0.031$, females $=0.048$ ). 
Table 2. Descriptive Statistics Twelfth Grade Sample ( $\mathrm{n}=721$ ).

\begin{tabular}{llcccccccc}
\hline Variable & \multicolumn{4}{c}{ Totals } & \multicolumn{3}{c}{ Males } & \multicolumn{3}{c}{ Females } \\
\hline Binge Drinking & mean & St. dev & Min/max & mean & St. dev & Min/max & mean & St. dev & Min/max \\
GPA & 0.11 & -- & $0-1$ & 0.13 & -- & $0-1$ & 0.09 & -- & $0-1$ \\
Mother's Education & 6.14 & 2.10 & $1-9$ & 5.79 & 2.120 & $1-9$ & 6.38 & 2.14 & $1-9$ \\
Working Mother & 4.06 & 1.30 & $1-6$ & 4.25 & 1.310 & $1-6$ & 4.07 & 1.40 & $1-6$ \\
Single Parent & 0.95 & -- & $0-1$ & 0.94 & -- & $0-1$ & 0.95 & -- & $0-1$ \\
Urbanacity & 0.57 & -- & $0-1$ & 0.53 & -- & $0-1$ & 0.60 & -- & $0-1$ \\
Geography & 0.38 & -- & $0-1$ & 0.42 & -- & $0-1$ & 0.36 & -- & $0-1$ \\
Cohort 2013 & 0.67 & -- & $0-1$ & 0.60 & -- & $0-1$ & 0.67 & -- & $0-1$ \\
Baseball & 0.33 & -- & $0-1$ & 0.32 & -- & $0-1$ & 0.34 & -- & $0-1$ \\
Basketball & 0.09 & -- & $0-1$ & 0.09 & -- & $0-1$ & 0.09 & -- & $0-1$ \\
Cheerleading & 0.32 & -- & $0-1$ & 0.49 & -- & $0-1$ & 0.22 & -- & $0-1$ \\
Football & 0.08 & -- & $0-1$ & 0.01 & -- & $0-1$ & 0.13 & -- & $0-1$ \\
Tennis & 0.18 & -- & $0-1$ & 0.42 & -- & $0-1$ & 0.02 & -- & $0-1$ \\
Track & 0.02 & -- & $0-1$ & 0.04 & -- & $0-1$ & 0.02 & -- & $0-1$ \\
Wrestling & 0.20 & -- & $0-1$ & 0.23 & -- & $0-1$ & 0.19 & -- & $0-1$ \\
\hline
\end{tabular}




\section{Step 2}

Following step one of the current dissertation's analysis, step 2 involves bivariate statistics. Given that the variables are categorical, tetrachoric correlations are appropriate (Vaswani, 1950). Tetrachoric correlations provide a product moment estimation. Examination of bivariate correlations is also vital to the assessing multicollinearity between variables. Multicolinearity occurs when more than one variable measures the same concept and results in inflated standard errors and biased coefficients (Berry \& Feldman, 1985). As no variables in either model are related at very high levels (.90) multicolinearity is not problematic.

Table 3 presents the correlation matrix for the eight and tenth grade sample of African-Americans. Within the eight and tenth grade sample positive correlations between binge drinking are found with being suspended from school (0.36) and being a member of the wrestling team (0.23). Binge drinking is negatively associated with residing in an urban area (-0.12) and playing tennis $(-0.28)$. These findings are relevant to the current study's hypothesis in that different sports have been associated with participation in binge drinking and in different directions. 
Table 3. Tetrachoric Correlation Between Variables Eighth and Tenth Grade Sample ( $\mathrm{n}=2197)$. (1) (2) (3) (4) (5) (6) (7) (8) (9) (10) (11) (12) (13) (14) (15)

\begin{tabular}{|c|c|c|c|c|c|c|c|c|c|c|c|c|c|c|c|}
\hline (1) & 1.00 & & & & & & & & & & & & & & \\
\hline (2) & $-0.55^{*}$ & 1.00 & & & & & & & & & & & & & \\
\hline (3) & -0.03 & $0.19 *$ & 1.00 & & & & & & & & & & & & \\
\hline (4) & 0.06 & 0.04 & -0.04 & 1.00 & & & & & & & & & & & \\
\hline (5) & $0.07 *$ & $0.05^{*}$ & 0.03 & $-0.29 *$ & 1.00 & & & & & & & & & & \\
\hline (6) & 0.01 & $-0.10^{*}$ & $0.27^{*}$ & -0.04 & $-0.11^{*}$ & 1.00 & & & & & & & & & \\
\hline (7) & $0.06^{*}$ & $0.06^{*}$ & 0.03 & $0.09 *$ & $-0.06^{*}$ & -0.01 & 1.00 & & & & & & & & \\
\hline$(8)$ & 0.02 & -0.04 & -0.03 & $-0.13 *$ & $-0.09 *$ & $0.09^{*}$ & 0.03 & 1.00 & & & & & & & \\
\hline (9) & $0.11 *$ & $-0.09 *$ & $0.14 *$ & -0.02 & 0.02 & $0.42 *$ & 0.03 & $0.31 *$ & 1.00 & & & & & & \\
\hline (10) & $0.09 *$ & -0.03 & $-0.08 *$ & 0.08 & $0.06^{*}$ & $-0.73 *$ & -0.01 & $0.08^{*}$ & $-0.03 *$ & 1.00 & & & & & \\
\hline (11) & 0.03 & $-0.09 *$ & $0.14^{*}$ & -0.05 & 0.02 & $0.80^{*}$ & 0.03 & $0.31^{*}$ & $0.47 *$ & $-0.44^{*}$ & 1.00 & & & & \\
\hline (12) & 0.05 & $-0.14^{*}$ & $-0.10 *$ & -0.17 & $-0.12 *$ & $-0.09 *$ & -0.06 & $0.31^{*}$ & $0.24^{*}$ & $0.14^{*}$ & 0.04 & 1.00 & & & \\
\hline (13) & 0.04 & $-0.09 *$ & $0.07 *$ & 0.01 & 0.03 & -0.25 & 0.01 & $0.16^{*}$ & $0.25^{*}$ & $0.11^{*}$ & $0.23 *$ & $0.17 *$ & 1.00 & & \\
\hline (14) & 0.01 & -0.06 & $0.17 *$ & -0.08 & $-0.12 *$ & $0.51 *$ & $0.11^{*}$ & $0.27^{*}$ & $0.25^{*}$ & 0.04 & $0.55^{*}$ & $0.23 *$ & $0.29 *$ & 1.00 & \\
\hline (15) & -0.01 & 0.04 & $0.36^{*}$ & $-0.12 *$ & -0.01 & -0.03 & $0.07 *$ & 0.06 & 0.01 & $0.09^{*}$ & 0.01 & $-0.28 *$ & 0.03 & $0.23 *$ & 1.00 \\
\hline
\end{tabular}

(1) Mother's Working Status, (2) Single Parent Household, (3) suspended, (4) Urbanacity, (5) geography, (6) male, (7) cohort 2013, (8) baseball, (9) basketball, (10) cheerleading, (11) football, (12) tennis, (13) track, (14) wrestling, (15) binge drinking 
Residing in a single parent household is positively associated with being suspended from school (0.19). Previous research has indicated that single parenting can affect delinquency through social bonds and peer association (Aizer, 2004; Griffin et al., 2000). Single parenting is negatively associated with having a working mother $(-0.55)$, being male, playing football (-0.09), basketball (-0.09), tennis (-0.14), and track(-0.09). Having a working mother is positively associated with residing in the south (0.07), playing basketball (0.11), and cheerleading (.09). Living in the southern United States is positively associated with cheerleading (.06). Living in the southern United States is negatively associated with residing in a rural area (-0.29), and playing tennis (-0.12), and wrestling (-0.12).

Being male is positively associated with school suspensions ( 0.27$)$, playing baseball (0.09), football (0.80), basketball (0.42), and wrestling (0.51). Being male is negatively associated with participation in cheerleading (-0.72). Residing in an urban area is negatively associated with paying baseball (-0.13). School suspensions are positively associated with football (0.14), basketball (0.14), track (0.07), and wrestling (0.17). In some ways this finding is consistent with previous research in that power sports, football and wrestling, were related to greater levels of general delinquency in the form of school suspensions (Kreager, 2007; Endresen \& Olweus, 2005) School suspension are negatively associated with playing tennis (-0.17). Furthermore, this is supportive of previous research involving the protective effect of sport on delinquency as being mostly associated with non-power sports (Hart \& Mueler, 2012). Playing baseball is positively associated with every other sport (basketball $=0.31$, cheerleading $=0.08$, football $=0.31$, tennis $=0.31$, track $=0.16$, wrestling $=0.27$ ). In other words, those who played baseball are 
significantly likely to play football, basketball, tennis, track, and cheerleading. Playing football is positively associated with participating in basketball (0.47), track (0.23), and wrestling (0.55). Playing football is negatively associated with participating in cheerleading (-0.44). Playing basketball is positively associated with participation in tennis $(0.24)$, track $(0.25)$ and wrestling $(0.25)$ while negatively associated with being a cheerleading (-0.30). Participation in track is positively associated with wrestling $(0.29)$ and cheerleading (0.11). This finding indicates the need for multivariate analysis in order examine the direct and controlled effect of each sport on binge drinking behaviors.

Table 4 includes a techtracoric correlation matrix for the twelfth grade sample of African-Americans. As shown in the twelfth grade sample the dependent measure of binge drinking is significantly and positively associated with being male (0.15), playing baseball (0.18), playing basketball (0.15) and playing football (0.33). While binge drinking is significantly and negatively associated with residing in the southern united states $(-0.26)$. Thus, the study's main hypothesis is again supported in that different sports are related to binge drinking in bivariate analysis.

Having a working mother is positively associated with playing football $(0.29)$. Living with a single parent is positively associated with residing in an urban area $(0.20)$. Residing in a single parent household is significantly and negatively associated with having a working mother (-0.21), being male (-0.13), and playing football $(0.12)$. Residing in the southern United States is negatively associated with being male (-.15), playing basketball (-0.15), playing football (-0.14), and wrestling (-0.25). Being male is positively associated with basketball $(0.50)$, football (0.81), track (0.27), and wrestling 
(0.58). Being male is negatively associated with cheerleading (-0.57). Living in an urban area is positively associated with playing basketball and football.

Again, many of the sport participation variables are interrelated. Playing baseball is positively associated with basketball $(0.28)$, cheerleading $(0.24)$, and wrestling $(0.37)$. Playing basketball is associated with football $(0.58)$ and track (0.39). Playing football is positively associated with track (.45) and wrestling (.33). Playing football is negatively associated with cheerleading $(-0.45)$. Playing tennis is positively associated with wrestling $(0.50)$. To isolate the effect of power port participation, multivariate analysis is needed. 
Table 4. Tetrachoric Correlation Between Variables 12 grade sample $(\mathrm{n}=721)$.

\begin{tabular}{|c|c|c|c|c|c|c|c|c|c|c|c|c|c|c|}
\hline & $(1)$ & (2) & (3) & (4) & (5) & (6) & (7) & $(8)$ & (9) & $(10)$ & $(11)$ & (12) & (13) & $(14)$ \\
\hline$(1)$ & 1.00 & & & & & & & & & & & & & \\
\hline (2) & $-0.21 *$ & 1.00 & & & & & & & & & & & & \\
\hline (4) & -0.06 & 0.01 & $-0.11 *$ & 1.00 & & & & & & & & & & \\
\hline (5) & 0.05 & $-0.13 *$ & 0.08 & $-0.15 *$ & 1.00 & & & & & & & & & \\
\hline (6) & 0.06 & 0.04 & 0.07 & -0.02 & -0.07 & 1.00 & & & & & & & & \\
\hline (7) & -0.14 & $0.18^{*}$ & 0.06 & -0.10 & -0.07 & -0.04 & 1.00 & & & & & & & \\
\hline (8) & 0.06 & -0.02 & $0.20 *$ & $-0.15 *$ & $0.50 *$ & -0.04 & $0.28 *$ & 1.00 & & & & & & \\
\hline (9) & 1.00 & 0.07 & -0.16 & $0.22 *$ & $-0.57 *$ & $0.15^{*}$ & $0.24 *$ & $-0.22 *$ & 1.00 & & & & & \\
\hline (10) & $0.29 *$ & $-0.12 *$ & 0.07 & $-0.14 *$ & $0.81 *$ & -0.04 & 0.13 & $0.58 *$ & $-0.45^{*}$ & 1.00 & & & & \\
\hline (11) & 1.00 & -0.01 & -0.15 & 0.03 & 0.08 & $0.24 *$ & $0.33 *$ & 0.01 & 0.15 & -0.01 & 1.00 & & & \\
\hline (12) & 0.19 & -0.03 & 0.04 & 0.21 & $0.27 *$ & 0.03 & 0.05 & $0.39 *$ & 0.06 & $0.45 *$ & $0.25^{*}$ & 1.00 & & \\
\hline (13) & -0.03 & -0.01 & $-0.30 *$ & $-0.25 *$ & $0.58 *$ & -0.16 & $0.37 *$ & $0.21 *$ & $0.18 *$ & $0.44 *$ & $0.50^{*}$ & $0.22 *$ & 1.00 & \\
\hline (14) & 0.10 & 0.10 & -0.09 & $-0.25 *$ & $0.14^{*}$ & 0.04 & $0.18^{*}$ & $0.15^{*}$ & 0.04 & $0.33^{*}$ & -0.11 & 0.07 & 0.11 & 1.00 \\
\hline
\end{tabular}

(1) Mother's Working Status, (2) Single Parent Household, , (3) Urbanacity, (4) geography, (5) Male (6) cohort 2013, (7) baseball, (8) basketball, (9) cheerleading, (10) football, (11) tennis, (12) track, (13) wrestling, (14) binge drinking 


\section{Step 3}

The third step in the analysis involves multivariate statistics, namely binary logistic regression. Table 5 presents results from binary logistic regression analysis of our demographic and sports participation variables as explanatory factors of participation in binge drinking within the previous two-weeks' time frame for the eighth and tenth grade sample of African-Americans. Coefficients, standard errors, and odds ratios are presented. Positive and significant predictors of binge drinking during this time included residing in being suspended from school, having a low GPA, belonging to the 2013 year of data collection, and being a member of the wrestling team. In other words, participating in wrestling, having a working mother and being suspended from school made someone more likely to participate in binge drinking within the last 2 weeks.

Significant and negative predictors of binge drinking included residing in an urban residential location, residing in the southern United States and playing tennis. In other words, those who lived in an urban area and played tennis made individuals less likely to participate in binge drinking. To test goodness of fit the Nagelkerke R-square is utilized. According to the Nagelkerke R-square, the model explains 10 percent of the factors in binge drinking.

These results are in line with our theoretical premises under study. In terms of binge drinking, the current study lends support to the parental attachment (i.e. social bond), deviant peer association (i.e., social learning), and power sport perspectives. Low grade point averages have been found related to delinquency in past research as related to a youth's low levels of attachment to school, commitment to making good grades, and involvement in Priscila activities such as homework and studying (Hirschi, 1969). Youth 
who have been suspended from school have lower levels of attachment to school and are more likely to form deviant peer associations (Eith, 2010). Finally, wrestling is in line with the power sport hypothesis (Endresen \& Olweus, 2005; Kreager, 2007). These findings are supportive of our main hypothesis in that participation in different sports is related to different levels of binge drinking. Wrestling, a sport involving antisocial and aggressive activities is positively related to binge drinking. Theoretically, previous research has found power sports to be related to deviant peer association leading to social learning of delinquent behaviors (Kreager, 2007). While our finding of tennis player being less likely to binge drink is related to our hypothesis of some sports having a protective effect over substance use. Theoretically, the protective effects associated with sport participation can come in the form of social bonds such as the previous research showing athletes to have greater levels of attachment to their schools, high levels of prosocial involvement and commitment, and greater likelihood for prosocial beliefs (Crosnoe 2001; Eccles \& Barber, 1999; Juvonen et al., 2012; Larson 1994; McNeal, 1995). According to previous research, non-power sports are the type most likely to be related to social bonds that deter delinquency (Crosnoe, 2001). 
Table 5. Logistic Regression Analysis Eighth and Tenth Grade Sample (n=2197).

\begin{tabular}{lccl}
\hline Item & $\mathrm{B}$ & $\mathrm{SE}$ & OR \\
\hline GPA & $-0.16^{*}$ & 0.05 & 0.85 \\
Mother's Education & -0.20 & 0.07 & 0.97 \\
Mother's Working Status & 0.09 & 0.30 & 1.09 \\
Single Parent & -0.01 & 0.21 & 0.98 \\
Suspended & $1.10^{*}$ & 0.24 & 3.15 \\
Male & -0.33 & 0.28 & 3.15 \\
Urbanacity & $-0.98^{*}$ & 0.33 & 0.37 \\
Geography & $-0.18^{*}$ & 0.21 & 0.83 \\
Cohort 2013 & $0.45^{*}$ & 0.21 & 1.58 \\
Baseball & 0.48 & 0.31 & 1.61 \\
Basketball & 0.34 & 0.24 & 1.03 \\
Cheerleading & 0.48 & 0.32 & 1.63 \\
Football & -0.51 & 0.31 & 0.60 \\
Tennis & $-1.99^{*}$ & 0.99 & 0.13 \\
Track & 0.02 & 0.26 & 1.01 \\
Wrestling & $1.25^{*}$ & 0.38 & 3.47 \\
Model Chi-square & $95.25^{*}$ & & \\
& & & \\
Nagelkerke R-Square & 0.10 & & \\
\hline
\end{tabular}

$* \mathrm{P}<.05$

Following the eighth and tenth grade samples binary logistic regression was performed with the twelfth grade sample of African-Americans. These results are presented in table 6 . Regarding the sports participation variables, participating in football is a significant and positive predictor of binge drinking behaviors. Furthermore, residing in the southern region of the United States is a significant and negative predictor of binge drinking. The Nagelkerke R-square shows that nearly the model explained 11 percent of the factors in binge drinking.

This finding is supportive of the power sport hypothesis as found in previous research (Endresen \& Olweus, 2005; Kreager, 2007) and the current dissertation's hypotheses regarding certain sports, power and contact sports and team sports, being related to binge drinking. Similar to the results from the eighth and tenth grade samples sport participation involving antisocial and aggressive activities, this time football, is 
related to binge drinking. Theoretically, previous research has found power and contact sports related to greater levels of deviant peer association (Kreager, 2007) that can result in the social learning of deviant behaviors. Furthermore, football, a team sport, can be examined through our theoretical lenses in that the cultural and social aspects of the team environment may be pushing pro-substance norms, and positive deviance (Hughes \& Coakley, 1990).

Table 6. Logistic Regression Analysis 12th grade Sample ( $\mathrm{n}=721)$.

\begin{tabular}{lccc}
\hline Item & $\mathrm{B}$ & $\mathrm{SE}$ & OR \\
\hline GPA & -0.07 & 0.11 & 0.92 \\
Mother's Education & 0.24 & 0.14 & 1.27 \\
Mother's Working Status & -0.46 & 0.88 & 0.63 \\
Single Parent & 0.60 & 0.41 & 1.83 \\
Male & 0.04 & 0.47 & 0.96 \\
Urbanacity & -0.37 & 0.47 & 0.69 \\
Geography & $-1.09^{*}$ & 0.38 & 0.33 \\
Cohort 2013 & 0.51 & 0.22 & 1.65 \\
Baseball & -0.02 & 0.57 & 0.98 \\
Basketball & 0.24 & 0.47 & 1.26 \\
Cheerleading & 0.64 & 0.64 & 1.89 \\
Football & $1.32^{*}$ & 0.52 & 3.74 \\
Tennis & -1.11 & 1.15 & 0.32 \\
Track & -0.04 & 0.44 & 0.96 \\
Wrestling & -1.11 & 1.18 & 0.33 \\
Model Chi-square & $33.29^{*}$ & & \\
Nagelkerke R-Square & & & \\
\hline
\end{tabular}
$* \mathrm{P}<.05$

Furthermore, the current study analyzes the predictive abilities of our variables through comparative gender specific models. This is done to assess the current dissertations third hypothesis that gender will moderate the effect of sport participation on binge drinking. Previous research shows sport and extracurricular activities to have 
different effects on delinquency based on gender (Fredrick \& Eccles, 2006; Hart \& Mueller, 2005). Presented in table 7 is regression results for the female sample of eighth and tenth grade African-Americans. Within the female sample, we can see that having been suspended from school and having a low GPA are positive and significant predictors of binge drinking with the past two weeks. Sport participation appeared to have no effect on the likelihood of females participating in binge drinking within the eighth and tenth grade samples. Model fit assessment through the Nagelkerke R-square shows that 9 percent of variance in binge drinking is explained by our independent variables.

This finding is contrary to previous literature that found girls' sport participation to be related to alcohol use. (Taylor \& Turek, 2010). However, this remains significant to our theoretical premises in that students who underperform in school have been found to have weaker school bonds and be involved in more forms of delinquency (Hirschi, 1969). Furthermore, school suspensions are related to deviant peer association and weaker school bonds (Arum \& Beattie, 1999; Eith, 2010).

Regarding the breakdown of male African-Americans and the effect of sport participation on binge drinking, binary logistic regression results are presented in table 7 . Results indicated that participation in wrestling is a significant and positive predictor of binge drinking. Furthermore, having been suspended from school is a significant and positive predictor of binge drinking. The Nagelkerke R-square indicated that nearly 10 percent of the variation in binge drinking is explained by the model. Thus, within the male sample, we found support for the current dissertation's hypothesis in that belonging to the wrestling team, a power sport, is a significant and positive predictor of binge 
drinking behaviors. Simultaneously, other sports are associated with binge drinking behaviors. Furthermore, being suspended from school is related to our theoretical premises in that previous research shows suspensions to be related to deviant peer associations, and involvement in deviant activities. Ultimately, the breakdown of sport participation's effect on binge drinking according to gender has shown that sport participation is more important to males than females in assessing their decision to binge drink. 
Table 7. Logistic Regression Analysis Eighth and Tenth Grade Males $(n=1118)$ and females $(n=1033)$.

\begin{tabular}{|c|c|c|c|c|c|c|c|}
\hline \multirow[t]{2}{*}{ Item } & \multicolumn{2}{|c|}{ B } & \multicolumn{2}{|c|}{ SE } & \multicolumn{2}{|c|}{ OR } & \multirow[b]{2}{*}{$\mathrm{Z}$} \\
\hline & Males & Females & Males & Females & Males & Females & \\
\hline GPA & -0.12 & $-0.20^{*}$ & 0.67 & 0.05 & 0.88 & 0.81 & -0.12 \\
\hline Mother's Education & -0.04 & -0.01 & 0.10 & 0.11 & 0.95 & 0.99 & -0.21 \\
\hline Mother's Working Status & 0.42 & -0.12 & 0.68 & 0.36 & 1.52 & 0.88 & 0.71 \\
\hline Single Parent & 0.02 & -0.04 & 0.32 & 0.28 & 1.02 & 0.96 & 0.14 \\
\hline Suspension & $10.29 *$ & $1.08^{*}$ & 1.54 & 0.89 & 3.65 & 0.29 & 5.26 \\
\hline Urbanacity & $-0.93 *$ & $-1.08 *$ & 0.18 & 0.17 & 0.39 & 0.33 & 0.22 \\
\hline Geography & -0.09 & -0.29 & 0.26 & 0.21 & 0.91 & 0.74 & 0.62 \\
\hline Cohort 2013 & $0.21 *$ & $0.65^{*}$ & 0.32 & 0.57 & 1.22 & 1.92 & -0.67 \\
\hline Baseball & 0.62 & 0.33 & 0.81 & 0.63 & 1.86 & 1.39 & 0.24 \\
\hline Basketball & -0.19 & 0.30 & 0.26 & 0.45 & 0.82 & 1.36 & -0.96 \\
\hline Cheerleading & 1.04 & 0.44 & 1.97 & 0.55 & 2.83 & 1.56 & 0.29 \\
\hline Football & -0.67 & 0.16 & 0.18 & 0.71 & 0.50 & 1.17 & -1.16 \\
\hline Tennis & -1.06 & -- & 0.29 & -- & 0.34 & -- & -- \\
\hline Track & -0.06 & 0.08 & 0.34 & 0.40 & 0.93 & 1.09 & -0.26 \\
\hline Wrestling & $1.35^{*}$ & -0.22 & 1.56 & 0.69 & 3.86 & 0.79 & 0.54 \\
\hline Model Chi-square & $55.67 *$ & $44.72 *$ & & & & & \\
\hline Nagelkerke R-Square & 0.100 & 0.09 & & & & & \\
\hline
\end{tabular}

$* \mathrm{P}<.05$ 
The analysis of the data from the twelfth grade sample of African-Americans continued with a gender specific analysis. Presented in table 8 includes the logistic regression results involving the female sample of twelfth graders. Results indicated that residing in a single parent households is a significant and positive predictor if binge drinking. While residing in the southern region of the United States is a significant and negative predictor. Again, sport participation is not significant in terms of predicting binge drinking by females. Model fit assessment through the Nagelkerkle R-square indicated that the model explained approximately 22 percent of the variance in binge drinking. Although, the female models of the current dissertation are not supportive of the main hypothesis, the theoretical premises are still at work. As consistent with previous research, single parent households can be related to delinquency such as substance use due to the weaker social bonds to family and greater opportunity for deviant peer association through less parental monitoring (Aizer, 2004; Grffin et al., 2000; Hirschi, 1969).

Following the female sample, results involving the male sample of twelfth grade African-Americans is presented in table 8. None of the variable include are significant predictors of binge drinking. The Nagelkerke R-square showed that the model explained 10 percent of the variance in binge drinking behaviors among the sample. Contrary to the eighth and tenth grade sample, sport participation is not associated with binge drinking behaviors in the gendered analysis of twelfth graders and thus not supportive of the current dissertation's main hypotheses. However, as examined through our theoretical premises this finding can be attributed to the greater prosocial bonds that previous research has supported from sport participation (Jordan, 1999; Mcneal, 1995). The next 
chapter discusses the impact of current study on theory and practice including potential policy implications. 
Table 8. Logistic Regression Analysis Twelfth Grade Males $(n=311)$ and Females $(n=410)$.

\begin{tabular}{|c|c|c|c|c|c|c|c|}
\hline Item & & & & & & & \\
\hline & Males & Females & Males & Females & Males & Females & $\mathrm{Z}$ \\
\hline GPA & -0.19 & 0.02 & 0.17 & 0.19 & 0.83 & 1.02 & -0.84 \\
\hline Mother's Education & 0.15 & 0.30 & 0.21 & 0.22 & 1.17 & 1.35 & -0.50 \\
\hline Mother's Working Status & -0.83 & -- & 1.07 & -- & 0.44 & -- & -- \\
\hline Single Parent & -0.04 & $1.41 *$ & 0.60 & 0.73 & 0.95 & 4.13 & -1.54 \\
\hline Urbanacity & 0.40 & -0.90 & 0.63 & 0.67 & 1.49 & 0.40 & 0.14 \\
\hline Geography & 0.03 & $-1.90 *$ & 0.54 & 0.66 & 1.04 & 0.15 & 2.27 \\
\hline Cohort 2013 & -0.62 & 0.27 & 0.54 & 0.54 & 1.86 & 1.30 & -1.17 \\
\hline Baseball & -1.39 & 0.45 & 1.01 & 0.77 & 0.24 & 1.57 & -1.44 \\
\hline Basketball & 0.25 & 0.45 & 0.58 & 0.84 & 1.28 & 1.58 & -0.19 \\
\hline Cheerleading & -- & 0.50 & -- & 0.88 & -- & 1.65 & -- \\
\hline Football & 0.80 & 1.88 & 0.61 & 0.99 & 2.23 & 6.55 & -0.93 \\
\hline Tennis & -- & 0.24 & -- & 0.92 & -- & 1.27 & -- \\
\hline Track & 0.58 & -0.47 & 0.62 & 0.85 & 1.80 & 0.62 & 1.00 \\
\hline Wrestling & -0.56 & -- & 1.06 & -- & 0.56 & -- & -- \\
\hline Constant & -1.59 & -3.80 & 1.49 & 0.16 & 0.20 & 0.02 & 1.48 \\
\hline Model Chi-square & 14.12 & 44.72 & & & & & \\
\hline Nagelkerke R-Square & 0.10 & 0.09 & & & & & \\
\hline
\end{tabular}

$* \mathrm{P}<.05$ 


\section{CHAPTER V \\ CONCLUSION}

Chapter one outlined the problem of youth binge drinking among AfricanAmericans and the influence of sport participation in accordance with the social bond (Hirschi, 1969) and social learning (Akers, 1998) theoretical perspectives. Chapter two further detailed the theoretical premises of social bond (Hirschi, 1969) and social learning (Akers, 1998) and included previous research related to binge drinking and sport participation among youth. Chapter three described the sample, data, and variables to be analyzed in the current dissertation. Chapter four presented the hypothesized results of data analysis including the proposed descriptive statistics and logistic regression analysis of independent and dependent variables. Chapter five will frame the results in terms of our theoretical premises and make suggestions for policy implications regarding youth sport participation and binge drinking.

\section{Conclusion}

The current dissertation analyzed survey data from 2 nationally representative samples of African-American youth. The hypothesis of the current dissertation is that participation in certain sports will be positively associated with binge drinking in a national sample of African-American youth. Specifically, the sport participation variables under study included football, basketball, baseball, tennis, track, cheerleading, and wrestling. Binge drinking in the past 2 weeks served as the study's dependent variable. 
The current dissertation hypothesized that power sports (e.g., football and wrestling) in particular will be significant and positive predictors of binge drinking. While non-power sports will have less significant relationships to binge drinking. Data analysis is supportive of this hypothesis.

The current dissertation's findings, in line with previous research (Endresen \& Olweus, 2005; Kreager, 2007, McCauley et al., 2014), lend some support to the idea that sports involving antisocial or aggressive activities, in particular, are related to delinquency such as binge drinking. The power sport hypothesis has been shown relevant to violence among athletes, bullying, gender inequitable attitudes, relationship abuse, and truancy (Endresen \& Olweus, 2005; Kreager, 2007, McCauley et al., 2014). The current dissertation expands the power sport hypothesis into binge drinking by youth in that football and wrestling participation is positively associated with binge drinking. The current dissertation includes two theoretical premises to frame these findings.

The theoretical perspectives of social bond (Hirschi, 1969) and social learning (Akers, 1998) have been found relevant to binge drinking and sport participation (Ecceles \& Barber, 1999; Hughes \& Coakley, 1991; Kreager, 2007; Marsh \& Kleitman, 2003) and they are vital in contextualizing the current study's findings. Scholars have proposed that sport participation can be studied according to the social bond premise in that participation has been found to raise levels of school attachment (Marsh \& Kleitman, 2003), increase a youth's commitment to prosocial activities (Eccles \& Barber, 1999), provide an opportunity for prosocial involvement (McNeal, 1995), and can be associated with prosocial beliefs (Larson, 1994). However, these findings are not universal (Miller et al., 2007) and as the current dissertation found, certain sports were more likely be 
associated with binge drinking. Thus, the results from the current dissertation did not fully support the contention that all sport participation increases social bonds and thus lowers delinquency in the form of binge drinking. However, the current study's finding of tennis participation being negatively related to binge drinking is consistent with previous research that finds heightened social bonds among athletes to be most relevant to non-power and contact sports (Crosnoe 2001; Eccles \& Barber, 1999; Juvonen et al., 2012; Larson 1994; McNeal, 1995).

Regarding social learning theory, previous research has shown sports participation to be a gateway to deviant peer association, especially with power sports (Kreager, 2007). Peer groups, such as sports teams can be pushing antisocial beliefs or positive deviance (Hughes \& Coakley, 1991). Positive deviance (Hughes \& Coakley, 1991) refered to how some activities such as drug use can be considered deviant by the larger society but within the context of sports teams for example, are modeled and reinforced as acceptable behaviors. The current dissertation's hypothesis that team sports will be greater predictors of binge drinking over individual sports as found in previous research (Obrien \& Lyons, 2000) is partially supported by the finding of football's positive relationship with binge drinking found in previous research. Team sports, especially can direct individual behaviors towards group norms through unique cultural and environmental pressures (Warr, 2002).

Regarding the demographic variables single parenting, school suspensions, and low GPAs were also found to be significant predictors of binge drinking among AfricanAmerican youth. These variables were also highly relevant to the current dissertation's theoretical premises. Past studies has shown that residing with a single parent can effect 
youth behavioral problems including alcohol use in many ways (Griffin, Bitvin, Scheier, Diaz, \& Miller, 2000; Lucero, Barret, \& Jensen, 2015; Osbourne, 2007; Vanaache, Sodermans, Matthijs \& Spicewood, 2013). Youth residing with single parents have less of an opportunity to develop strong parental attachment and are more likely to be exposed to deviant peers (Griffin et al., 2000).

Regarding school suspensions, studies have shown that students who have been suspended from school have weaker social bonds towards their school (Eith, 2010), with the bond of involvement obviously related to time spent in school. Further, school suspensions have been found a pathway to deviant peer association, unsupervised free time to spent in further delinquency, and reduced time with conforming classmates (Arum \& Beattie, 1999). Previous research has also identified low GPAs to be related to delinquency (Hirschi, 1969). Theoretically, this can framed according to lesser levels of involvement and commitment towards school.

\section{Policy Implications}

The connection between youth sports and delinquency is vital as sport participation plays a significant cultural and social role in the lives of young African American athletes (Bimper, Harrison, \& Clark, 2012). Sport participation holds many opportunities for heightened social status and educational advancement in the form of scholarships (Holland \& Andre, 1994). This cultural and social significance lends itself to the necessity for policy implications directed towards athletes with the goal of reducing delinquency associated with specific sport participation. Based on the results of the 
analysis in support of the current dissertation's hypothesis, reductions in youth binge drinking can occur by targeting power sport participants.

Several programs and policies exist with an intent to educate and help steer athletes clear of binge drinking. However, the current dissertation's findings emphasize the need for programs designed especially for targeting power sport participants and some support for the targeting of team sports over individual sports. Furthermore, programs designed to aid in the development of positive social bonds and a reduction on negative social learning experiences in sport participation are needed. For example, the Athletes Training and Learning to Avoid Steroids (ATLAS) program is a promising initiative for high school students.

The program educates high school level youth about the harms of steroids, alcohol, and illicit drugs on sport participation and future life consequences. Although the program has been delivered to mostly white middle-class youth, evaluation results encourage implementation to more diverse racial and economic backgrounds (Goldberg, Mackinnon, Elliot, Moe, Clarke, \& Cheong, 2000). The program is relevant to the social learning premise as posttest findings showed a heightened perception of coach intolerance of binge drinking, greater abilities to refuse drug offers from peers, and lower likelihoods to believe advertisements for substances among athletes.

Another example, Sport Prevention Plus Wellness (formerly project sport) is a brief intervention related to school based physical activities. The program targets youth with recreational and exercise interests designed to reduce alcohol and drug use among high school students. The program combines positive messages about physical activity 
with messages about drug and alcohol use prevention. The program is based on the Integrative Behavioral-Image Model (BIM), where positive personal and social images serve to motivate healthy behaviors and avoiding drugs and alcohol.

The program contains a one-time health behavioral screening and fitness consultation previously delivered at sport physical examinations. Evaluation results revealed SPORT Prevention Plus Wellness (Project SPORT) held several positive and statistically significant results at 3-month follow up for alcohol use including use, quantity, heavy use, stage of initiation, and heavy use of alcohol (Welch, Moore, Diclemente, Bledsoe, \& Jobli, 2005). Similar results were found for negative expectancy beliefs, behavioral capabilities, and perceived susceptibility. Other positive results were found regarding parental monitoring and parent-child communication. Theoretically, these findings are related to the current dissertation's theoretical perspectives through raising youth's negative beliefs and attitudes towards binge drinking, subjective norms, peer influences, and parent child bonding.

Furthermore, as participation in certain types of athletics is a significant predictor of binge drinking encouraging mandatory drug use in schools directed towards athletes may be beneficial. For example, the SATURN (Student Athlete Testing Using Random Notification) program was funded by the National Institute on drug abuse and designed to prevent binge drinking among high school athletes through random drug tests. Consequences of positive drug tests intended to be less punitive than criminal justice system involvement including parental notification, counseling referral, and game suspensions. Evaluation research regarding binge drinking testing programs have been mixed and further research is need to claim their efficacy (DuPont, Merlo, Arria, \& Shea, 
2012). However, theoretically, drug testing programs are relevant to the current dissertation's theoretical perspectives in that some research has found student beliefs regarding parental and school intolerance to drug use, as communicated through testing, resulted in lower rates of use in some studies (DuPont, Merlo, Arria, \& Shea, 2012).

\section{Limitations}

Although the findings remain meaningful, the current dissertation has several limitations. First, with all survey research, limitations involving sample size and design may limit the accuracy of the estimates. Bias may have been introduced by the failure to obtain data from 100 percent of the students from participating schools and by schools refusal to participate. Furthermore, the African-American subgroup is subjected to a larger margin of sampling error due to the cluster sampling and limited number of cases.

Second, the use of many single item indicators on the survey questionnaire is potentially troubling for reliability and validity and limitations of variance explained by one variable. Third, the study lacks some substances that are likely to be found among athletes including steroids, painkillers, Adderall, energy drinks and a measure of polydrug use and a measure of youth who play multiple sports. A third limitation refers to the time of year that the questionnaire was delivered. The measures of binge drinking over short time frames (previous 2 weeks) could potentially obtain different results at different times of the year according to when the sport is in season. The seasons of sport participation such as fall (football), spring (basketball, wrestling), may prevent substance using behaviors simply by athletes not wanting to use alcohol during the in-season of their sports. Fourth, the data is cross-sectional making casual inferences between sport 
participation and binge drinking difficult. This causal relationship may be established by calling on future research with longitudinal and experimental designs.

Despite these limitations, the current dissertation concludes that through an analysis of nationally representative samples of African-American youth our main hypotheses are supported. Hypothesis 1, the type of sport that an individual participates in would provide a difference in binge drinking among African-American youth, is supported through the individual and unique effects that some sports provided in logistic regression analysis. Some sports (e.g. football and wrestling) show a positive link to binge drinking while other sports show a negative link to binge drinking (e.g. tennis).

Hypothesis 2, consistent with the literature (Endresen \& Olweus, 2005; Kreager, 2007, McCauley et al., 2014) power sport participation would result in African-American youth binge drinking, is supported in that both of the power sports (e.g. football and wrestling) included in the study show positive effects on binge drinking through logistic regression analysis. These findings are related to the social bond, social learning, and power sport hypothesis as seen in previous research. Power sports have been found related to delinquency and deviant peer relationships (Hughes \& Coakley, 1991; Kreager, 2007). Furthermore, the protective effects of prosocial bonding that can results from sport participation have been most associated with non-power sports (Hart \& Mueller, 2012; McNeal, 1995). Hypothesis 3, gender will moderate the effect of sport participation on binge drinking was only supported with wrestling participation in the eighth and tenth grade sample and not supported in the twelfth grade sample. 


\section{REFERENCES}

Abbey, A., Jacques, A. J., Hayman, L. W., \& Sobeck, J. (2006). Predictors of early substance use among African American and Caucasian youth from urban and suburban communities. Merrill-Palmer Quarterly, 52(2), 305-326.

Aizer, A. (2004). Home alone: Supervision after school and child behavior. Journal of Public Economics, 88(9), 1835-1848.

Akers, R. L. (1998). Social structure and social learning. Los Angeles: Roxbury.

Akers, R. L., \& Lee, G. (1996). A longitudinal test of social learning theory: Adolescent smoking. Journal of Drug Issues, 26(2), 317-343.

Akers, R. L., \& Jensen, G. F. (2006). The empirical status of social learning theory of crime and deviance: The past, present, and future. Taking stock: The status of criminological theory, 15, 37-76.

Arum, R., \& Beattie, I. (1999). High school experience and the risk of adult incarceration. Criminology, 37, 515-537.

Eith, C. A. (2005). Delinquency, schools, and the social bond. New York, NY: LFB Scholarly Publishing LLC

Bahr, S. J., Hoffmann, J. P., \& Yang, X. (2005). Parental and peer influences on the risk of adolescent drug use. Journal of Primary Prevention, 26(6), 529-551.

Bennett, J. C. (1990). The irrationality of interscholastic football as a means of preparing adolescents for adulthood. Perceptual and Motor Skills, 71, 802.

Bennett, J. C. (1991). The irrationality of the catharsis theory of aggression as justification for educators' support of interscholastic football. Perceptual and motor skills, 72(2), 415-418.

Berry, W. D., \& Feldman, S. (1985). Multiple regression in practice (No. 50). New York: Sage. 
Beyer, J. M. \&. Hannah D. (2000). The cultural significance of athletics in U.S. higher education. Journal of Sport Management, 14, 105-132.

Bimper Jr, A. Y., Harrison Jr, L., \& Clark, L. (2013). Diamonds in the rough: Examining a case of successful Black male student athletes in college sport. Journal of Black Psychology, 39(2), 107-130.

Bond, L., Butler, H., Thomas, L., Carlin, J., Glover, S., Bowes, G., \& Patton, G. (2007). Social and school connectedness in early secondary school as predictors of late teenage substance use, mental health, and academic outcomes. Journal of Adolescent Health, 40(4), 357-e9.

Bouchery, E. E., Harwood, H. J., Sacks, J. J., Simon, C. J., \& Brewer, R. D. (2011). Economic costs of excessive alcohol consumption in the US, 2006. American journal of preventive medicine, 41(5), 516-524.

Booth, J., Farrell, A., \& Varano, S. P. (2008). Social bond, serious delinquency, and risky behavior: A gendered analysis. Crime Delinquency, 54, 423 - 456.

Bradizza, C. M., Reifman, A., \& Barnes, G. M. (1999). Social and coping reasons for drinking: predicting alcohol misuse in adolescents. Journal of Studies on Alcohol, 60(4), 491-499.

Bryant, A. L., \& Zimmerman, M. A. (2002). Examining the effects of academic beliefs and behaviors on changes in substance use among urban adolescents. Journal of Educational Psychology, 94(3), 621.

Burton, K. A., Florell, D., \& Wygant, D. B. (2013). The role of peer attachment and normative beliefs about aggression on traditional bullying and cyberbullying. Psychology in the Schools, 50(2), 103-115.

Cammarota, J. (2004). The gendered and racialized pathways of Latina and Latino youth: Different struggles, different resistances in the urban context. Anthropology \& Education Quarterly, 35(1), 53-74. 
Cheng, S., \& Klugman, J. (2010). School racial composition and biracial adolescents' school attachment. The Sociological Quarterly, 51(1), 150-178.

Coleman, J. S. (1961). The adolescent society: The social life of the teenager and its impact on education.

Cooper, M. L. (2002). Alcohol use and risky sexual behavior among college students and youth: evaluating the evidence. Journal of Studies on Alcohol, supplement, (14), 101117.

Crosnoe, R. (2001). The social world of male and female athletes in high school. In Sociological Studies of Children and Youth (pp. 89-110). Emerald Group Publishing Limited.

Curtin, S. C., Ventura, S. J., \& Martinez, G. M. (2014). Recent declines in nonmarital childbearing in the United States (No. 2014). US Department of Health and Human Services, Centers for Disease Control and Prevention, National Center for Health Statistics.

Dams-O'Connor, K., Martin, J. L., \& Martens, M. P. (2007). Social norms and alcohol consumption among intercollegiate athletes: The role of athlete and nonathlete reference groups. Addictive behaviors, 32(11), 2657-2666.

D'Apoloto, R., \& Wan-Tatah, V. (1998). Social bonding and juvenile male violence: An empirical investigation. Free Inquiry in Creative Sociology, 26(1), 11-22.

Denham, B. E. (2011). Alcohol and marijuana use among American high school seniors: Empirical associations with competitive sports participation. Sociology of Sport Journal, 28(3), 362-379.

Demanet, J., \& Van Houtte, M. (2012). School belonging and school misconduct: The differing role of teacher and peer attachment. Journal of Youth and Adolescence, 41(4), 499-514.

Dimeff, L. A., Kilmer, J., Baer, J. S., \& Marlatt, G. A. (1995). Binge drinking in college. JAMA, 273(24), 1903-1904. 
Dukes, R. L., Martinez, R. O., \& Stein, J. A. (1997). Precursors and consequences of membership in youth gangs. Youth \& Society, 29(2), 139-165.

DuPont, R. L., Merlo, L. J., Arria, A. M., \& Shea, C. L. (2013). Random student drug testing as a school-based drug prevention strategy. Addiction, 108(5), 839-845.

Eccles, J. S., \& Barber, B. L. (1999). Student council, volunteering, basketball, or marching band what kind of extracurricular involvement matters?. Journal of adolescent research, 14(1), 10-43.

Eder, D., \& Kinney, D. A. (1995). The effect of middle school extra curricular activities on adolescents' popularity and peer status. Youth \& Society, 26(3), 298-324.

Eitle, D., Turner, R. J., \& Eitle, T. M. (2003). The deterrence hypothesis reexamined: Sports participation and substance use among young adults. Journal of Drug Issues, $33(1), 193-221$.

Ellickson, S. L., Tucker, J. S., Klein, D. J., \& McGuigan, K. A. (2001). Prospective risk factors for alcohol misuse in late adolescence. Journal of studies on alcohol, 62(6), 773-782.

Endresen, I. M., \& Olweus, D. (2005). Participation in power sports and antisocial involvement in preadolescent and adolescent boys. Journal of Child Psychology and Psychiatry, 46(5), 468-478.

Estrada Jr., J. N., Gilreath, T. D., Astor, R. A., \& Benbenishty, R. (2014). Gang membership, school violence, and the mediating effects of risk and protective behaviors in California high schools. Journal of School Violence, 13(2), 228-251.

Ewing, B. T. (1998). High school athletes and marijuana use. Journal of Drug Education, $28(2), 147-157$.

Fejgin, N. (1994). Participation in high school competitive sports: A subversion of school mission or contribution to academic goals?. Sociology of sport journal, 11(3), 211230. 
Feldman, A. F., \& Matjasko, J. L. (2005). The role of school-based extracurricular activities in adolescent development: A comprehensive review and future directions. Review of educational research, 75(2), 159-210.

Ford, J. A. (2007). Substance use among college athletes: A comparison based on sport/team affiliation. Journal of American College Health, 55(6), 367-373.

Ford, J. A. (2008). Social learning theory and nonmedical prescription drug use among adolescents. Sociological Spectrum, 28(3), 299-316.

Ford, J. A. (2009). Nonmedical prescription drug use among adolescents the influence of bonds to family and school. Youth \& Society, 40(3), 336-352.

Fredricks, J. A., \& Eccles, J. S. (2005). Developmental benefits of extracurricular involvement: Do peer characteristics mediate the link between activities and youth outcomes?. Journal of Youth and Adolescence, 34(6), 507-520.

Fredricks, J. A., \& Eccles, J. S. (2006). Is extracurricular participation associated with beneficial outcomes? Concurrent and longitudinal relations. Developmental Psychology, 42, 698-713.

Gatz, M., Messner, M. A., \& Ball-Rokeach, S. (Eds.). (2002). Paradoxes of youth and sport. SUNY Press.

Gogtay, N., Giedd, J. N., Lusk, L., Hayashi, K. M., Greenstein, D., Vaituzis, A. C., ... \& Rapoport, J. L. (2004). Dynamic mapping of human cortical development during childhood through early adulthood. Proceedings of the National academy of Sciences of the United States of America, 101(21), 8174-8179.

Goldberg, L., MacKinnon, D. P., Elliot, D. L., Moe, E. L., Clarke, G., \& Cheong, J. (2000). The adolescents training and learning to avoid steroids program: preventing drug use and promoting health behaviors. Archives of Pediatrics \& Adolescent Medicine, 154(4), 332-338.

Green, G. A., Uryasz, F. D., Petr, T. A., \& Bray, C. D. (2001). NCAA study of substance use and abuse habits of college student-athletes. Clinical journal of sport medicine, $11(1), 51-56$. 
Griffin, K. W., Botvin, G. J., Scheier, L. M., Diaz, T., \& Miller, N. L. (2000). Parenting practices as predictors of substance use, delinquency, and aggression among urban minority youth: Moderating effects of family structure and gender. Psychology of addictive behaviors: journal of the Society of Psychologists in Addictive Behaviors, 14(2), 174.

Gruber, A. J., Pope, H. G., Hudson, J. I., \& Yurgelun-Todd, D. (2003). Attributes of long-term heavy cannabis users: a case-control study. Psychological Medicine, 33(08), 1415-1422.

Hagan, J., Shedd, C., \& Payne, M. R. (2005). Race, ethnicity, and youth perceptions of criminal injustice. American sociological review, 70(3), 381-407.

Hahm, H. C., Kolaczyk, E., Jang, J., Swenson, T., \& Bhindarwala, A. M. (2012). Binge drinking trajectories from adolescence to young adulthood: the effects of peer social network. Substance use \& misuse, 47(6), 745-756.

Hahm, H. C., Lahiff, M., \& Guterman, N. B. (2004). Asian American adolescents' acculturation, binge drinking, and alcohol-and tobacco-using peers. Journal of Community Psychology, 32(3), 295-308.

Hart, C. O., \& Mueller, C. E. (2013). School delinquency and social bond factors: Exploring gendered differences among a national sample of 10th graders. Psychology in the Schools, 50(2), 116-133.

Heimer, K., \& Matsueda, R. L. (1994). Role-taking, role commitment, and delinquency: A theory of differential social control. American Sociological Review, 365-390.

Henry, K. L., Knight, K. E., \& Thornberry, T. P. (2012). School disengagement as a predictor of dropout, delinquency, and problem substance use during adolescence and early adulthood. Journal of youth and adolescence, 41(2), 156-166.

Henry, K. L., \& Slater, M. D. (2007). The contextual effect of school attachment on young adolescents' alcohol use. Journal of school health, 77(2), 67-74.

Heyman, S. R. (1986). Psychological problem patterns found with athletes. Clinical 
Psychologist.

Hildebrand, K. M., Johnson, D. J., \& Bogle, K. (2001). Comparison of patterns of alcohol use between high school and college athletes and non-athletes. College Student Journal, 35(3), 358-366.

Hingson, R., Heeren, T., Winter, M., \& Wechsler, H. (2005). Magnitude of alcoholrelated mortality and morbidity among US college students ages 18-24: Changes from 1998 to 2001. Annu. Rev. Public Health, 26, 259-279.

Hoeve, M., Stams, G. J. J., van der Put, C. E., Dubas, J. S., van der Laan, P. H., \& Gerris, J. R. (2012). A meta-analysis of attachment to parents and delinquency. Journal of abnormal child psychology, 40(5), 771-785.

Hoffmann, J. P. (2006). Extracurricular Activities, Athletic Participation, and Adolescent Alcohol Use: Gender-Differentiated and School-Contextual Effects*. Journal of health and social behavior, 47(3), 275-290.

Holland, A., \& Andre, T. (1994). Athletic participation and the social status of adolescent males and females. Youth \& Society, 25(3), 388-407.

Hope, L. C., \& Cook, C. C. (2001). The role of Christian commitment in predicting drug use amongst church affiliated young people. Mental Health, Religion \& Culture, 4(2), 109-117.

Huber, P.J., 1967. The behavior of maximum likelihood estimates under non-standard conditions. In: Proceedings of the Fifth Berkeley Symposium on Mathematical Statistics and Probability, University of California Press, Berkeley, pp. 221-233.

Huebner, A. J., \& Betts, S. C. (2002). Exploring the utility of social control theory for youth development issues of attachment, involvement, and gender. Youth \& Society, 34(2), 123-145.

Hughes, R., \& Coakley, J. (1991). Positive deviance among athletes: The implications of overconformity to the sport ethic. Sociology of sport journal, 8(4), 307-325. 
Jenkins, P. H. (1997). "School Delinquency and The School Social Bond." Journal of Research in Crime and Delinquency 34 (3):337-368.

Johnson, B. R., Jang, S. J., Larson, D. B., \& De Li, S. (2001). Does adolescent religious commitment matter? A reexamination of the effects of religiosity on delinquency. Journal of Research in Crime and Delinquency, 38(1), 22-44.

Johnson, M. K., Crosnoe, R., \& Elder Jr, G. H. (2001). Students' attachment and academic engagement: The role of race and ethnicity. Sociology of Education, 318340.

Johnston, L. D., O’Malley, P. M., Bachman, J. G., \& Schulenberg, J. E. (2013). Monitoring the future national results on drug use: 2012 overview, key findings on adolescent drug use. Ann Arbor: Institute for Social Research, The University of Michigan, 168.

Jordan, W. J. (1999). Black high school students' participation in school-sponsored sports activities: Effects on school engagement and achievement. Journal of Negro Education, 54-71.

Junger, M., \& Marshall, I. H. (1997). The interethnic generalizability of social control theory: An empirical test. Journal of Research in Crime and Delinquency, 34(1), 79112.

Juvonen, J., Espinoza, G., \& Knifsend, C. (2012). The role of peer relationships in student academic and extracurricular engagement. In Handbook of research on student engagement (pp. 387-401). Springer US.

Kempf, K. (1993). The empirical status of Hirschi's control theory. In F. Adler \& W. Laufer (Eds.), New directions in criminological theory: Advances in criminological theory (Vol. 4, pp. 143-186). New Brunswick, NJ: Transaction Publishers.

Kreager, D. A. (2007). Unnecessary roughness? School sports, peer networks, and male adolescent violence. American sociological review, 72(5), 705-724.

Kreager, D. A., \& Haynie, D. L. (2011). Dangerous liaisons? Dating and drinking diffusion in adolescent peer networks. American sociological review, 76(5), 737-763. 
Krohn, M. D., \& Massey, J. L. (1980). Social control and delinquent behavior: An examination of the elements of the social bond. The Sociological Quarterly, 21(4), $529-543$.

Langbein, L., \& Bess, R. (2002). Sports in school: Source of amity or antipathy?. Social Science Quarterly, 83(2), 436-454.

Larson, R. (1994). Youth organizations, hobbies, and sports as developmental contexts. Adolescence in context: The interplay of family, school, peers, and work in adjustment, 46-65.

Leonard, K. K., \& Decker, S. H. (1994). The theory of social control: Does it apply to the very young?. Journal of criminal justice, 22(2), 89-105.

Li, S. D. (2004). The impacts of self-control and social bonds on juvenile delinquency in a national sample of midadolescents. Deviant Behavior, 25(4), 351-373.

Li, Y., Zhang, W., Liu, J., Arbeit, M. R., Schwartz, S. J., Bowers, E. P., \& Lerner, R. M. (2011). The role of school engagement in preventing adolescent delinquency and substance use: A survival analysis. Journal of Adolescence, 34(6), 11811192.

Longshore, D., Chang, E., Hsieh, S. C., \& Messina, N. (2004). Self-control and social bonds: A combined control perspective on deviance. NCCD news, 50(4), 542-564.

Losen, D. J., \& Gillespie, J. (2012). Opportunities suspended: The disparate impact of disciplinary exclusion from school.

Lucero, J. L., Barrett, C., \& Jensen, H. (2015). An examination of family and school factors related to early delinquency. Children \& Schools, cdv013.

Lumley, T. (2004). Analysis of complex survey samples. Journal of Statistical Software, $9(1), 1-19$.

Marsh, H. W., \& Kleitman, S. (2003). School athletic participation: Mostly gain with little pain. Journal of Sport and Exercise Psychology, 25(2), 205-228.

Mahoney, J. L. (2000). School extracurricular activity participation as a moderator in the development of antisocial patterns. Child development, 71(2), 502-516. 
Mahoney, J. L., \& Cairns, R. B. (1997). Do extracurricular activities protect against early school dropout?. Developmental psychology, 33(2), 241.

Martens, M. P., Cox, R. H., \& Beck, N. C. (2003). Negative consequences of intercollegiate athlete drinking: the role of drinking motives. Journal of Studies on Alcohol, 64(6), 825-828.

McCauley, H. L., Jaime, M. C. D., Tancredi, D. J., Silverman, J. G., Decker, M. R., Austin, S. B., ... \& Miller, E. (2014). Differences in adolescent relationship abuse perpetration and gender-inequitable attitudes by sport among male high school athletes. Journal of Adolescent Health, 54(6), 742-744.

McNeal Jr, R. B. (1995). Extracurricular activities and high school dropouts. Sociology of education, 62-80.

Menasco, M. A. (2005). A reconsideration of social control theory: Understanding the interwoven nature of the social bond, academic performance and juvenile delinquency.

Miller, K. E., Melnick, M. J., Barnes, G. M., Sabo, D., \& Farrell, M. P. (2007). Athletic involvement and adolescent delinquency. Journal of youth and adolescence, 36(5), 711.

Mulia, N., Ye, Y., Greenfield, T. K., \& Zemore, S. E. (2009). Disparities in alcoholrelated problems among White, Black, and Hispanic Americans. Alcoholism: Clinical and Experimental Research, 33(4), 654-662.

Nelson, T. F., Naimi, T. S., Brewer, R. D., \& Wechsler, H. (2005). The state sets the rate: the relationship among state-specific college binge drinking, state binge drinking rates, and selected state alcohol control policies. American Journal of Public Health, 95(3), 441-446.

Nelson, T. F., \& Wechsler, H. (2001). Alcohol and college athletes. Medicine \& Science in Sports \& Exercise.

O’Brien, C. P., \& Lyons, F. (2000). Alcohol and the athlete. Sports Medicine, 29(5), 295 300 . 
O'brien, K. S., Blackie, J. M., \& Hunter, J. A. (2005). Hazardous drinking in elite New Zealand sportspeople. Alcohol and Alcoholism, 40(3), 239-241.

Okamoto, D. G., Herda, D., \& Hartzog, C. (2013). Beyond good grades: School composition and immigrant youth participation in extracurricular activities. Social science research, 42(1), 155-168.

Osborne, C. (2007). Is marriage protective for all children? Cumulative risks at birth and subsequent child behavior among urban families. Working Paper 2007-09-Fragile Families.

Otto, L. B., \& Alwin, D. F. (1977). Athletics, aspirations, and attainments. Sociology of Education, 102-113.

Pacific Institute for Research and Evaluation. (2005). Drinking In America: Myths, Realities, and Prevention Policy.

Partington, S., Partington, E., Heather, N., Longstaff, F., Allsop, S., Jankowski, M., ... \& Gibson, A. S. C. (2013). The relationship between membership of a university sports group and drinking behaviour among students at English Universities. Addiction Research \& Theory, 21(4), 339-347.

Peralta, R. L. (2007). College alcohol use and the embodiment of hegemonic masculinity among European American men. Sex roles, 56(11-12), 741-756.

Pederson, L. L., Poulin, M., Lefcoe, N. M., Donald, A. W., \& Hill, J. S. (1992). Does cigarette smoking affect the fitness of young adults? rationale and protocol for future research. The journal of sports medicine and physical fitness, 32(1), 96-105.

Peguero, A. A. (2012). The children of immigrants' diminishing perceptions of just and fair punishment. Punishment \& Society, 14(4), 429-451.

Peguero, A. A., Popp, A. M., Latimore, T. L., Shekarkhar, Z., \& Koo, D. J. (2011). Social control theory and school misbehavior: Examining the role of race and ethnicity. Youth violence and juvenile justice, 9(3), 259-275. 
Peretti-Watel, P., Guagliardo, V., Verger, P., Pruvost, J., Mignon, P., \& Obadia, Y. (2003). Sporting activity and drug use: alcohol, cigarette and cannabis use among elite student athletes. Addiction, 98(9), 1249-1256.

Pratt, T. C., Cullen, F. T., Sellers, C. S., Thomas Winfree Jr, L., Madensen, T. D., Daigle, L. E., ... \& Gau, J. M. (2010). The empirical status of social learning theory: A metaanalysis. Justice Quarterly, 27(6), 765-802.

Rehm, J., Taylor, B., Mohapatra, S., Irving, H., Baliunas, D., Patra, J., \& Roerecke, M. (2010). Alcohol as a risk factor for liver cirrhosis: A systematic review and metaanalysis. Drug and alcohol review, 29(4), 437-445.

Ryan, J. P., \& Testa, M. F. (2005). Child maltreatment and juvenile delinquency: Investigating the role of placement and placement instability. Children and Youth Services Review, 27(3), 227-249.

Ryan, J. P., Testa, M. F., \& Zhai, F. (2008). African American males in foster care and the risk of delinquency: The value of social bonds and permanence. Child Welfare, $87(1), 115$.

Sandford, R. A., Armour, K. M., \& Warmington, P. C. (2006). Re-engaging disaffected youth through physical activity programmes. British educational research journal, 32(2), 251-271.

Seydlitz, R. (1993). Complexity in the relationships among direct and indirect parental controls and delinquency. Youth \& Society, 24(3), 243-275.

Simons, R. L., \& Burt, C. H. (2011). Learning to be bad: Adverse social conditions, social schemas, and crime. Criminology, 49(2), 553-598.

Skinner, B. F. (1953). Science and human behavior. Simon and Schuster.

Small, E., Suzuki, R., \& Maleku, A. (2014). The Impact of Family and Parental Education on Adolescents' Substance Use: A Study of US High School Seniors. Social work in public health, 29(6), 594-605. 
Steele, J. L., Peralta, R. L., \& Elman, C. (2011). The co-ingestion of nonmedical prescription drugs and alcohol: a partial test of social learning theory. Journal of Drug Issues, 41(4), 561-585.

Stewart, E. A. (2003). School social bonds, school climate, and school misbehavior: A multilevel analysis. Justice Quarterly, 20(3), 575-604.

Stogner, J. M., \& Miller, B. L. (2013). Investigating the 'bath salt'panic: The rarity of synthetic cathinone use among students in the United States. Drug and alcohol review, 32(5), 545-549.

Strycker, L. A., Duncan, S. C., \& Pickering, M. A. (2003). The social context of alcohol initiation among African American and White youth. Journal of Ethnicity in Substance Abuse, 2(1), 35-42.

Substance Abuse and Mental Health Services Administration, Results from the 2013 National Survey on Drug Use and Health: Summary of National Findings, NSDUH Series H-48, HHS Publication No. (SMA) 14-4863. Rockville, MD: Substance Abuse and Mental Health Services Administration, 2014.

Taylor, M. J., \& Turek, G. M. (2010). If only she would play? The impact of sports participation on self-esteem, school adjustment, and substance use among rural and urban African American girls. Journal of Sport Behavior, 33(3), 315.

The U.S. Bureau of labor Statistics. (2016). Employment Characteristics of Families 2015. Retrieved from https://www.bls.gov/news.release/pdf/famee.pdf

Thombs, D. L., \& Hamilton, M. J. (2002). Effects of a social norm feedback campaign on the drinking norms and behavior of Division I student-athletes. Journal of drug education, 32(3), 227-244.

Townshend, J. M., \& Duka, T. (2005). Binge drinking, cognitive performance and mood in a population of young social drinkers. Alcoholism: Clinical and Experimental Research, 29(3), 317-325. 
Ueno, K. (2009, September). Same-Race Friendships and School Attachment: Demonstrating the Interaction Between Personal Network and School Composition1. In Sociological Forum (Vol. 24, No. 3, pp. 515-537). Blackwell Publishing Ltd.

Vanassche, S., Sodermans, A. K., Matthijs, K., \& Swicegood, G. (2014). The effects of family type, family relationships and parental role models on delinquency and alcohol use among Flemish adolescents. Journal of child and family studies, 23(1), 128-143.

Veliz, P., \& Shakib, S. (2012). Interscholastic Sports Participation and School Based Delinquency: Does Participation in Sport Foster a Positive High School Environment?. Sociological Spectrum, 32(6), 558-580.

Wallace, J. M., \& Muroff, J. R. (2002). Preventing substance abuse among African American children and youth: Race differences in risk factor exposure and vulnerability. The Journal of Primary Prevention, 22(3), 235-261.

Ward, B. W., \& Gryczynski, J. (2009). Social learning theory and the effects of living arrangement on heavy alcohol use: Results from a national study of college students. Journal of Studies on Alcohol and Drugs, 70(3), 364-372.

Warr, M. (2002). Companions in crime: The social aspects of criminal conduct. Cambridge University Press.

Werch, C., Moore, M. J., DiClemente, C. C., Bledsoe, R., \& Jobli, E. (2005). A Multihealth Behavior Intervention Integrating Physical Activity and Substance Use Prevention for Adolescents. Prevention Science, 6, 213-226.

Wechsler, H., Dowdall, G. W., Davenport, A., \& Rimm, E. B. (1995). A gender-specific measure of binge drinking among college students. American journal of public health, 85(7), 982-985.

White, H., 1982. Maximum likelihood estimation of misspeci2ed models. Econometrica $50,1-25$. 
Wiatrowski, M. D., Griswold, D. B., \& Roberts, M. K. (1981). Social control theory and delinquency. American sociological review, 525-541.

Wright, J. P., \& Cullen, F. T. (2000). Juvenile involvement in occupational delinquency. Criminology, 38(3), 863-896.

Yamagata, K., Ishida, K., Sairenchi, T., Takahashi, H., Ohba, S., Shiigai, T., ... \& Koyama, A. (2007). Risk factors for chronic kidney disease in a community-based population: a 10-year follow-up study. Kidney international, 71(2), 159-166. 


\section{CURRICULAM VITAE \\ Jason Nicholson \\ Department of Criminal Justice \\ University of Louisville \\ Louisville, KY 40292 \\ Phone: (859) 699-8447 \\ jason.nicholson@louisville.edu}

\section{EDUCATION}

$2017 \quad \mathrm{PhD} \quad$ University of Louisville - Criminal Justice

$2013 \quad$ MS Eastern Kentucky University - Criminal Justice

2011 BS Eastern Kentucky University - Criminal Justice

\section{ACADEMIC POSITIONS}

2014-Present Graduate Research and Teaching Assistant

University of Louisville, Louisville, KY

\section{OTHER PROFESSIONAL POSITIONS}

2015-Present Managing Editor: Journal of Criminal Justice Education

\section{PUBLICATIONS}

\section{PEER-REVIEWED JOURNAL ARTICLES}

Marcum, C.D., Higgins, G.E., \& Nicholson, J. (Accepted 2017). Crossing boundaries online in romantic relationships: An exploratory study of the perceptions of impact on partners by cyberstalking offenders. Deviant Behavior.

Marcum, C. D., Nicholson, J., \& Higgins, G. E. (Accepted 2016). I'm watching you: Cyberstalking behaviors of University students in romantic relationships. American Journal of Criminal Justice.

Houser, K., McCord, E. S., \& Nicholson, J. A. (Accepted 2016). The influence of neighborhood risk factors on parolee recidivism in Philadelphia, Pennsylvania. The Prison Journal. 
Nicholson, J., Dawson-Edwards, C., Higgins, G. E., \& Walton, I. (Accepted 2015). The non- medical use of pain relievers among African-Americans: A test of primary socialization theory. Journal of Substance Use.

\section{BOOK CHAPTERS}

Nicholson, J., \& Higgins, G. E. (2016). Social Learning Theory. In Brent Teasdale and Mindy Bradley (in-press). Preventing Crime and Violence: Springer.

\section{ENCYCLOPEDIA ENTRIES}

Nicholson, J., \& Higgins, G. E. (2016). Techniques of Neutralization. Encyclopedia of Juvenile Delinquency and Justice. Edited by Christopher Schreck.

McCord, E. S., \& Nicholson, J. (in press). AMBER Alerts. In B. Arrigo (Ed.), The Sage encyclopedia of surveillance, security, and privacy. Thousand Oaks, CA: Sage Publications.

McCord, E. S., \& Nicholson, J. (in press). Parks. In B. Arrigo (Ed.), The Sage encyclopedia of surveillance, security, and privacy. Thousand Oaks, CA: Sage Publications.

\section{WORKS IN PROGRESS}

Nicholson, J., \& Higgins, G. E., (in progress). An evaluation of the teens crime and the community and the community works program using propensity score matching. Criminal Justice Policy Review

Nicholson, J., Higgins, G. E., Dawson-Edwards, C., \& Walton, I., (Under Review). Binge drinking and African-Americans: A partial test of primary socialization theory. Deviant Behavior

Nicholson, J., \& Higgins, G. E., (in progress). Social learning theory and recreational inhalant use among Juveniles.

Nicholson, J., \& Higgins, G. E., (in progress). A critical appraisal of the propensity score matching literature in criminal justice 2000-2015.

Nicholson, J., \& Higgins, G. E., (in progress). The influence of athletic participation on marijuana use. 


\section{PRESENTATIONS}

\section{Conference Presentations}

Marcum, C., Higgins, G.E., \& Nicholson, J., "Cyberbullying: Examining the Role of SelfControl and Internet Addiction." Paper presentation at American Society of Criminology, New Orleans, LA, November 2016.

Nicholson, J., \& Higgins, G.E., "Exploring the Effectiveness of the Teens Crime and the Community and Community Works Delinquency Prevention Program Using Propensity Score Matching." Paper presentation at American Society of Criminology, New Orleans, LA, November 2016.

Marcum, C., Higgins, G.E., \& Nicholson, J., "The Electronic Leash and Romantic Relationships: Examining the Theoretical Predictors of Cyberstalking and its Perceived Impact by University Students." Paper presentation at Southern Criminal Justice Association, Savanah, GA, September 2016.

Marcum, C.D., Higgins, G.E., \& Nicholson, J., "Crossing Boundaries Online in Romantic Relationships: An Exploratory Study of the Perceptions of Impact on Partners by Cyberstalking Offenders." Paper presentation at Southern Criminal Justice Association, Savanah, GA, September 2016.

Nicholson, J., Higgins, G. E., Dawson-Edwards, C., \& Walton, I., "Binge Drinking and African-Americans: A Test of Primary Socialization Theory." Academy of Criminal Justice Sciences, Denver, CO, March 2016.

Nicholson, J., McCord, E, S., \& Houser, K., "Descriptive Analysis of Technical Offenses vs. New Crimes." Panel presentation at American Society of Criminology, Washington DC, November 2015.

Nicholson, J., Swartz, K., \& Keeling, D., "Exploring the Impact of Collective Efficacy, Disorder, and Crime on Citizens Attitudes towards the Police." Paper presentation at Southern Criminal Justice Association, Charleston, SC, September 2015.

Nicholson, J. \& Higgins, G., E., "Recreational Inhalant Use among Juveniles.” Paper presentation at Southern Criminal Justice Association, Charleston, SC, September 2015

Nicholson, J., McCord, E, S., \& Houser, K., “The Impact of Neighborhoods on Recidivism." Panel presentation at Academy of Criminal Justice Sciences, Orlando, FL, March 2015.

Nicholson, J. "Deceptive Tactics in Police Interrogations." Paper presentation at Academy of Criminal Justice Sciences, Orlando, FL, March 2015 
TEACHING EXPERIENCE

Courses Taught-Department of Criminal Justice, $U$ of $L$

Undergraduate

Statistics (2015)

Research Methods (2015) (2017)

Introduction to Law Enforcement (teaching assistant, 2014)

\section{PROFESSIONAL SERVICE}

Manuscript Reviewer

Journal of Criminal Justice Education

DEPARTMENT SERVICE

University of Louisville

Representative to Graduate Student Union

PROFESSIONAL REFERENCES

Dr. George E. Higgins

George.higgins@louisville.edu

502-852-0331

Dr. Gennaro Vito

Gennaro.vito@louisville.edu

502-852-6509

Dr. Deborah Keeling

Deborah.wilson@louisville.edu

502-852-0370 \& 502-852-2237 